OPEN ACCESS

Edited by:

Anna R Carta,

University of Cagliari, Italy

Reviewed by:

Giuseppina Cantarella,

University of Catania, Italy

Vinod Tiwari,

Indian Institute of Technology (BHU),

India

*Correspondence:

Hualin Cai

hualincai@csu.edu.cn

Specialty section:

This article was submitted to

Neuropharmacology,

a section of the journal

Frontiers in Pharmacology

Received: 15 February 2021

Accepted: 07 May 2021

Published: 24 May 2021

Citation:

Chen Q, Cao T, LiN, Zeng C, Zhang S, Wu X, Zhang B and Cai $H$ (2021) Repurposing of Anti-Diabetic Agents as a New Opportunity to Alleviate Cognitive Impairment in Neurodegenerative and

Neuropsychiatric Disorders. Front. Pharmacol. 12:667874. doi: 10.3389/fphar.2021.667874

\section{Repurposing of Anti-Diabetic Agents as a New Opportunity to Alleviate Cognitive Impairment in Neurodegenerative and Neuropsychiatric Disorders}

\author{
Qian Chen ${ }^{1,2}$, Ting Cao ${ }^{1,2}, \mathrm{NaNa}^{1} \mathrm{Li}^{1,2}$, Cuirong Zeng ${ }^{1,2}$, Shuangyang Zhang ${ }^{1,2}$, Xiangxin $\mathrm{Wu}^{1,2}$, \\ Bikui Zhang ${ }^{1,2}$ and Hualin Cai ${ }^{1,2 *}$ \\ ${ }^{1}$ Department of Pharmacy, The Second Xiangya Hospital, Central South University, Changsha, China, ${ }^{2}$ Institute of Clinical \\ Pharmacy, Central South University, Changsha, China
}

Cognitive impairment is a shared abnormality between type 2 diabetes mellitus (T2DM) and many neurodegenerative and neuropsychiatric disorders, such as Alzheimer's disease (AD) and schizophrenia. Emerging evidence suggests that brain insulin resistance plays a significant role in cognitive deficits, which provides the possibility of anti-diabetic agents repositioning to alleviate cognitive deficits. Both preclinical and clinical studies have evaluated the potential cognitive enhancement effects of antidiabetic agents targeting the insulin pathway. Repurposing of anti-diabetic agents is considered to be promising for cognitive deficits prevention or control in these neurodegenerative and neuropsychiatric disorders. This article reviewed the possible relationship between brain insulin resistance and cognitive deficits. In addition, promising therapeutic interventions, especially current advances in anti-diabetic agents targeting the insulin pathway to alleviate cognitive impairment in $A D$ and schizophrenia were also summarized.

Keywords: cognitive deficits, anti-diabetic agents, brain insulin resistance, alzheimer's disease, schizophrenia, type 2 diabetes mellitus

\section{INTRODUCTION}

Cognitive deficits can be observed in neurodegenerative and neuropsychiatric disorders, such as AD and schizophrenia with demonstratable brain pathology(Taber et al., 2010). Brain functional and structural abnormalities are related with cognitive deficits. Furthermore, brain changes could be a common biomarker for treatment-related cognitive improvement across neuropsychiatric disorders(Ott et al., 2019). Recent findings demonstrate that brain is a further important site of insulin resistance and brain insulin resistance is associated with cognitive dysfunction(Kullmann et al., 2016). Insulin resistance has been recognized as a mechanism of cognitive dysfunction in $\mathrm{T} 2 \mathrm{DM}$ (Kim, 2019). Additionally, in $\mathrm{AD}$, the impaired brain insulin signaling may contribute to cognitive decline via impaired hippocampal neuroplasticity, increased tau protein concentration, neuroinflammation and mitochondrial dysfunction(Biessels and Reagan, 2015). Given the relationship between brain insulin resistance and cognitive impairment, repurposing of already marketed anti-diabetic medications has attracted growing attention as a potential treatment in 


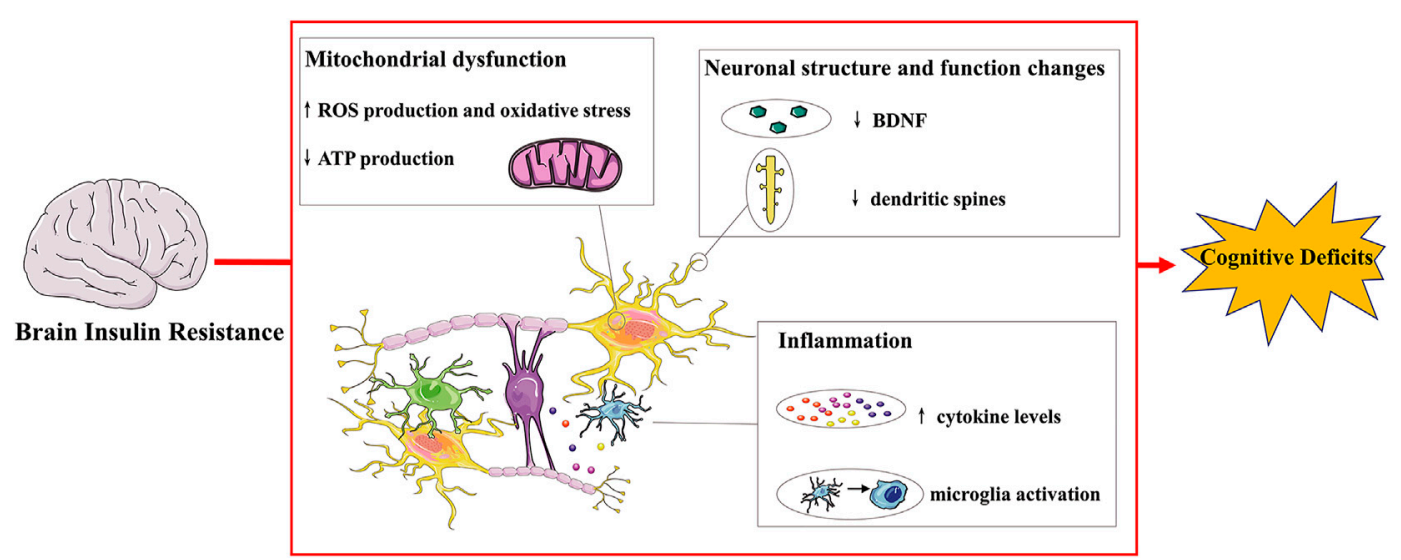

FIGURE 1 | Mechanisms connecting brain insulin resistance and cognitive deficits.Insulin receptors are distributed throughout the brain and their expression and action have also been found in neurons and glial cells. Brain insulin resistance impairs cognitive deficits via multiple ways. For instance, brain insulin resistance affects normal neuronal structure and function, resulting in decreased dendritic spines and BDNF levels and inducing impaired synaptic plasticity and transmission. Brain insulin resistance also exhibits cognitive decline with brain mitochondrial dysfunction with increased oxidative stress, leading to increased ROS and decreased ATP production. Additionally, brain insulin resistance induces raised inflammatory progress: microglia activation and increased cytokine levels, contributing to cognitive deficits. BDNF: brain derived neurotrophic factor; ROS: reactive oxygen species.

cognitive decline diseases. Specifically, both preclinical and clinical studies have demonstrated the neuroprotective effects of glucagon-like peptide 1 (GLP-1) receptor agonists, which are used for diabetes and obesity treatment(Mansur et al., 2018).

Accumulating studies have attracted profound scientific and public attention to the greater metabolic comorbidity of T2DM in schizophrenia patients(Mizuki et al., 2020), which is partly owing to overlapping genetic risk factors, environmental susceptibility and antipsychotic drugs-related mechanisms(Suvisaari et al., 2016; Hackinger et al., 2018). Even first-episode drug-naïve patients with schizophrenia exhibited greater insulin resistance compared with normal subjects(Pillinger et al., 2017). Glucose metabolic disturbances may be an inherent part of schizophrenia, and brain insulin resistance is a risk factor for cognitive deficits in this brain disorder(Wijtenburg et al., 2019). Meanwhile, the efficacy of current antipsychotic drugs on cognitive deficits are limited(Hill et al., 2010), making it urgent to develop procognitive strategies. But few investigations have been done to illuminate the precise mechanisms linking insulin resistance and cognitive deficits in schizophrenia. In addition, whether pro-cognitive strategies used in $\mathrm{AD}$ via their anti-diabetic effects or other mechanisms in the brain could be generalized to schizophrenia is uncertain. It is of utmost importance to develop and promote effective interventions to ameliorate cognitive deficits in individuals with schizophrenia, further understanding the underlying mechanisms behind cognitive dysfunction and improving the quality of life and clinical outcomes of patients.

This review briefly summarized the mechanisms linking brain insulin resistance and cognitive impairment. In the next section, we provided an overview of preclinical and clinical studies with the aim to explore the potential cognitive enhancement of some anti-diabetic agents in treating $\mathrm{AD}$ and schizophrenia.

\section{MECHANISMS CONNECTING BRAIN INSULIN RESISTANCE AND COGNITIVE DEFICITS}

Insulin is a peptide hormone secreted by $\beta$ cells of pancreatic islets, playing a crucial role in metabolism and cognitive function. Insulin resistance refers to a pathological condition of decreased insulin sensitivity of insulin-targeting cells and issues. In periphery, it has been recognized as a main feature of metabolic syndrome and T2DM. The brain is a further important site of insulin resistance, which is an extremely important organ to regulate energy metabolism, body weight, memory and cognition. Insulin receptor expression and action have also been found in neuronal populations and glial cells, and the disruption of insulin signaling in the brain is related to abnormal neuronal function(Kleinridders et al., 2014). In the brain, insulin resistance is associated with impaired neuroplasticity, raised inflammation process and mitochondrial dysfunction, underlining the significant role of brain insulin resistance in cognitive deficits (Figure 1).

\section{Brain Insulin Resistance and Abnormal Neuronal Structure and Function}

Neurons are the structural and functional units of nervous system and brain insulin resistance-induced neuronal injury leads to cognitive deficits. Brain insulin resistance is associated with reduced dendritic spines, decreased level of BDNF and impaired synaptic plasticity(Biessels and Reagan, 2015; Park et al., 2019).

Dendritic spines are small postsynaptic protrusive structures from a dendritic, which are essential for synaptic transmission, and ultimately for learning and memory function(Nakahata and Yasuda, 2018). Hippocampal dendritic spines are also regulated by BDNF and brain insulin resistance decreases hippocampal 
dendritic spine density and disrupts the production of BDNF(Ding et al., 2017), leading to reduced LTP in the hippocampus and impaired cognitive function(Xiang et al., 2015). The decreased level of BDNF in insulin resistant brain would affect mitochondrial and protein synthesis, influencing synaptogenesis and neuronal health(Tome-Carneiro et al., 2018). BDNF is secreted in response to stimulations and is dependent on calcium influx through voltage gated calcium channels or $\mathrm{N}$-methyl-d-aspartate (NMDA) receptors(Brigadski and Leßmann, 2020). Insulin resistance in the brain disrupted the NMDA receptor phosphorylation and final the production of BDNF(Ding et al., 2017). Besides, neuronal insulin resistance induced the down-regulation of cyclic element binding protein (CREB) and the expression of BDNF(Mi et al., 2017). And the decreased insulin resistance could stimulate the increased release of BDNF into the serum(Śmieszek et al., 2017).

Synaptic plasticity refers to numeral, structural and functional modifications of synapses under various stimulations, leading to the corresponding changes of the transmission efficacy(Citri and Malenka, 2008). In addition to resulting in decreased dendritic spines and reduced hippocampal BDNF levels, insulin resistance can cause deficits in brain synaptic plasticity, which together leading to impairment of cognitive function. Rats with specific downregulation of hippocampal insulin receptors by using a lentiviral vector exhibited impaired spatial learning and memory function through alterations in the expression and phosphorylation of glutamate receptor subunits(Grillo et al., 2015). Disruption of IRS-2 in the mice hippocampus impaired NMDA receptor-dependent LTP of synaptic transmission(Martin et al., 2012). Additionally, insulin resistance impaired synaptic plasticity and memory function through the hyper-palmitoylation of a-amino-3-hydroxy5methyl-4-isoxazole propionic acid (AMPA) glutamate receptor subunit GluA1 in the hippocampus(Spinelli et al., 2017). An impaired insulin signaling in the brain also changed integrin-linked kinase glycogen synthase kinase (GSK) $3 \beta$ signaling and reduced the trafficking and function of postsynaptic glutamate receptors, thereby impairing synaptic plasticity and contributing to cognitive decline(Shonesy et al., 2012).

\section{Brain Insulin Resistance and Inflammation}

Inflammation is the defensive response to stimuli occurring in the body and brain. In neuropathological disorders, raised inflammatory process (microglia activation and elevated cytokine levels) impairs cognitive performance through disrupting neurobiological mechanism: synaptic plasticity, neurogenesis, neurotrophic factors, the HPA axis and the kynurenine pathway(Fourrier et al., 2019). For instance, proinflammatory cytokines induce the activation of hippocampal indoleamine 2,3-dioxygenase, a tryptophan-catabolizing enzyme in the kynurenine pathway, which participates in learning and memory function(André et al., 2008; Too et al., 2016). The raised inflammatory process may promote the production of kynurenine, the NMDA antagonist, resulting in glutamatergic transmission dysregulation and eventually leading to cognitive impairment in schizophrenia(Müller, 2008). Additionally, immune-mediated imbalance of tryptophan catabolism via the kynurenine pathway is also associated with neuroinflammatory neurological disorders including $\mathrm{AD}$ (Maddison and Giorgini, 2015). The activation of the kynurenine pathway induced by inflammatory cytokines may generate neurotoxic metabolites including quinolinic acid and kynurenic acid, which are likely to play a role in the pathogenesis of $\mathrm{AD}$ (Gong et al., 2011).

Brain insulin resistance is associated with inflammation. High fat diet (HFD) rodents showed cognitive impairment with elevated Interleukin-1 $\beta$ (IL-1 $\beta$ )(Almeida-Suhett et al., 2017) and tumor necrosis factor a (TNFa) in the hippocampus(Boitard et al., 2014). Meanwhile, proinflammatory cytokines such as TNFa promoted the development of insulin resistance via interference with intracellular pathways(Shoelson et al., 2006). TNFa induced the activation of NF- $\kappa \beta$ signaling pathway and caspase 3 was associated with diabetic-induced cognitive deficits and insulin combination with tocotrienol exhibited promising cognitive enhancement in the diabetic rats(Kuhad et al., 2009). The dysregulated insulin signaling in the hippocampus activated microglia and astrocyte, decreased BDNF levels, and inhibited neurogenesis, leading to cognitive deficits(Liu et al., 2018).

\section{Brain Insulin Resistance and Mitochondrial Dysfunction}

Mitochondria are essential for neuronal activity and plasticity, and mitochondrial dysfunction leads to cortical underconnectivity: reduced dendrite, axon and synapse growth(Fernandez et al., 2019). Meanwhile, abnormalities in mitochondrial structure and function have been observed in psychiatric disease(Clay et al., 2011), and cell-free mitochondrial DNA fragment could be used as a biomarker for cognitive deficits in schizophrenia(Suárez-Méndez et al., 2020).

Insulin resistance is related with mitochondrial dysfunction and mitochondria-dependent high level of free radicals also induce insulin resistance(Yaribeygi et al., 2019). Rodents with brain-specific knockout of the insulin receptors exhibited brain mitochondrial dysfunction and dopamine dysfunction leading to behavioral disorder(Kleinridders et al., 2015). HFD-induced brain insulin resistance reduced mitochondrial ATP production rate and oxidative enzyme activities, increased ROS emission and oxidative stress(Ruegsegger et al., 2019). The decreased insulin signaling in the hippocampus resulted in cognitive decline accompanied with decreased mitochondrial oxidative phosphorylation complex proteins(Petrov et al., 2015). Additionally, the activation of insulin receptors and subsequent activation of the a submit of AMP-activated protein kinase (AMPK) improved brain mitochondrial biogenesis(Barhwal et al., 2015).

Although the basic pathologies of $\mathrm{AD}$ and schizophrenia are diverse, they still have some symptomatic similarities in addition to cognitive deficits(White and Cummings, 1996), suggesting a complex relationship between the two diseases(Youn et al., 2011). Moreover, new findings support a genetic liability between schizophrenia and psychosis in $\mathrm{AD}$ (Creese et al., 2019). For 
instance, various psychiatric symptoms such as positive and negative symptoms are highly prevalent in both $\mathrm{AD}$ and schizophrenia(White and Cummings, 1996). Additionally, some brain morphological data indicate that the neurodegenerative features like progressive brain tissue loss can also occur in patients with schizophrenia(Rund, 2009). The clinical and pathophysiologic analogies of $\mathrm{AD}$ and schizophrenia suggest that there are maybe some shared pathological underpinnings between these disorders, which may provide additional insights into the mechanisms underlying both disorders(White and Cummings, 1996). Brain insulin resistance may be one of the referred underpinnings. Compared with the general population, patients with $\mathrm{AD}$ are more vulnerable to T2DM(Janson et al., 2004). The Mayo Clinic Alzheimer Disease Patient Registry revealed that $81 \%$ of $\mathrm{AD}$ patients had either T2DM or an impaired fasting glucose level(Janson et al., 2004). Meanwhile, there is a 2- to 5-fold higher risk of T2DM in people with schizophrenia than in the general population(Ward and Druss, 2015). Although the original causes for cognitive impairment in $\mathrm{AD}$ and schizophrenia are somewhat different, similar disturbances in glucose metabolism and insulin signaling will undoubtedly have further negative impact on the cognitive function of both disorders. A study demonstrated that insulin sensitivity as indexed by HOMA value was negatively coupled with verbal fluency performance, brain size and temporal lobe gray matter volume in regions known to be involved in speech production in cognitively healthy, nondiabetic elderly men and women(Benedict et al., 2012). Furthermore, higher level of insulin resistance was an independent predictor of poor verbal fluency performance(Ekblad et al., 2017). As mentioned above, it is plausible that brain insulin resistance contributes to cognitive deficits in schizophrenia. A systematic review supported that metabolic syndrome including insulin resistance were associated with cognitive impairment in schizophrenia(Bora et al., 2016). Meanwhile, higher levels of glucose and insulin resistance were found in first-episode drug-naïve patients with schizophrenia who showed cognitive deficits and disruption of white matter structure(Zhang et al., 2019). The level of insulin resistance was elevated and correlated with the severity of cognitive impairment in first-episode drug-naïve patients with schizophrenia(Tao et al., 2020). However, lack of studies directly detects whether individuals with schizophrenia show brain insulin resistance. Recently, a study demonstrated the insulin signaling abnormalities in neuronal cells in first-episode drug-naïve patients with schizophrenia(Kapogiannis et al., 2019). Another study using magnetic resonance spectroscopy (MRS) to detect brain glucose metabolism found a relationship between lower brain glucose utilization and decreased memory measures in schizophrenia patients compared to controls(Wijtenburg et al., 2019). They also detected brain insulin resistance by blood Extracellular Vesicle (EV) biomarkers to verify the association between neuronal insulin resistance and brain glucose metabolism(Wijtenburg et al., 2019). It suggests that brain insulin resistance and glucose metabolism alteration play a part in the pathophysiological of cognitive dysfunction in schizophrenia. Central insulin action is relevant to cognition and cognitive dysfunction in schizophrenia could be linked to central insulin defects(Agarwal et al., 2020). Furthermore, drugs that can act as insulin sensitizers and/or bypass insulin resistance in the brain offer a unique opportunity to address cognitive deficits and improve lives of the patients with schizophrenia(Agarwal et al., 2019).

\section{REPURPOSING OF ANTI-DIABETIC AGENTS AS A POTENTIAL TREATMENT TARGETING COGNITIVE FUNCTION IN AD AND SCHIZOPHRENIA}

Current findings suggest that brain insulin resistance is associated with the development of cognitive deficits and anti-diabetic agents boosting insulin action in the brain present promising cognitive enhancement in T2DM and neurodegenerative diseases. Based on this opinion, targeting brain insulin resistance may have therapeutic potential to alleviate cognitive deficits in individuals with schizophrenia (Figure 2). Therefore, we summarized several anti-diabetic drugs targeting the insulin pathway to improve cognitive function which could be procognitive therapeutic interventions in $\mathrm{AD}$ and schizophrenia. Literature research (Figure 3: Flowchart of study selection) was conducted on PubMed (last: 8 April 2021) with the combinations of the key words: antidiabetic agents, cognitive impairment, Alzheimer disease, schizophrenia, neurodegenerative disorders, and neuropsychiatry. Inclusion criteria were: (1) animal models or patients with cognitive deficits; (2) under the treatment or supplement treatment of antidiabetic agents; (3) outcomes involved in cognitive function. Exclusion criteria were: (1) a review or a letter; (2) non-English language; (3) streptozocininduced diabetic animal models. Totally, 38 preclinical and 21 clinical studies were selected for this review (see Table 1 and Table 2 for details).

\section{Intranasal Insulin}

The reductions in the integrity of blood brain barrier may also be a contributing factor to the pathologic cascade leading to cognitive decline in neurodegenerative and neuropsychiatric disorders(Haar et al., 2016). Under the circumstances, intranasal insulin provides an advantageous and non-invasive technique to directly supply the brain with insulin to better target and bypass the blood brain barrier without significant influences on plasma insulin or glucose levels(Renner et al., 2012). Furthermore, intranasal insulin had a faster time course of absorption compared with subcutaneous insulin and the bioavailability of intranasal insulin was $8.3 \%$ compared with an intravenous bolus injection(Drejer et al., 1992). Studies demonstrated that intranasal insulin could improve memory function in cognitively impaired humans(Freiherr et al., 2013), providing the possibility that intranasal insulin was potentially a promising strategy to treat cognitive deficits. 


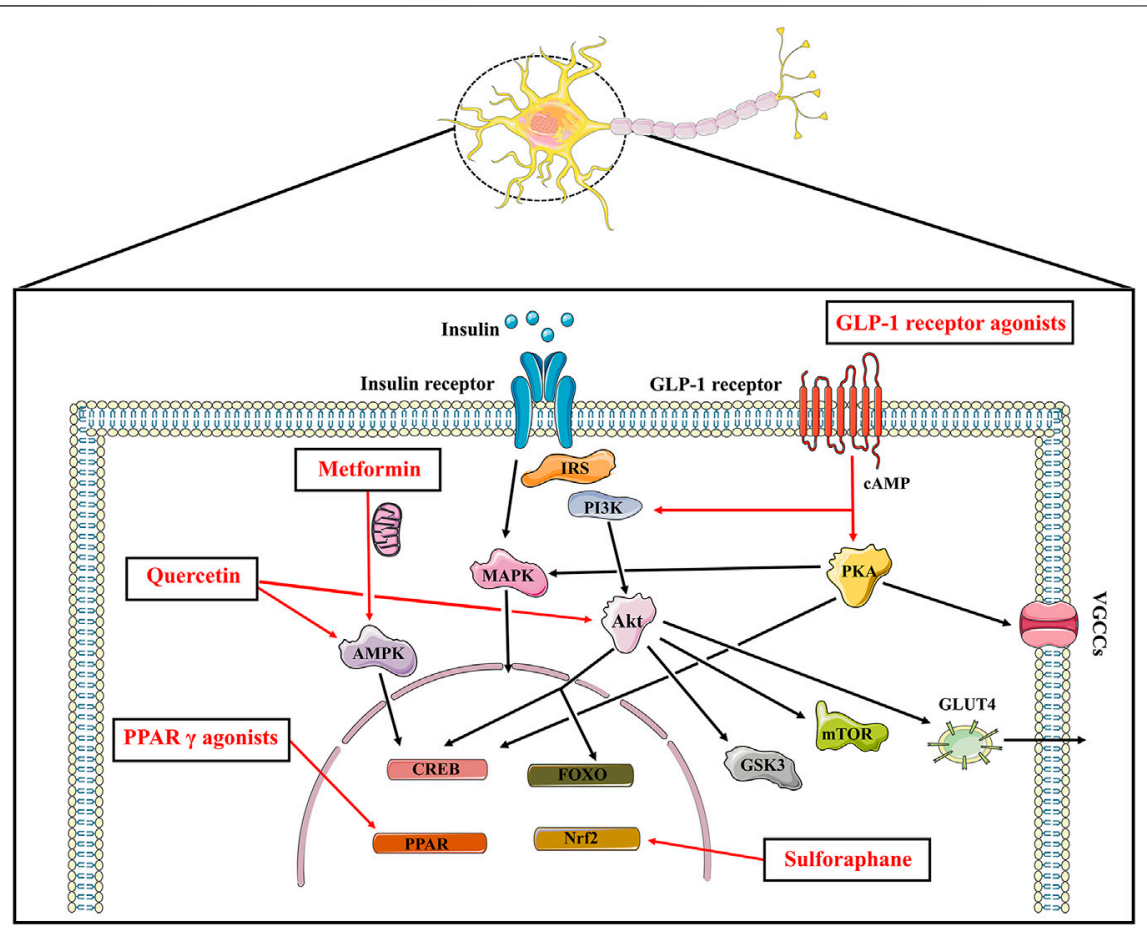

FIGURE 2 | The insulin signaling and the potential pro-cognitive effects of anti-diabetic agents. Insulin binds to insulin receptor to play its part, which promotes PI3K and Akt, the major downstream nodes of insulin signaling. The downstream targets of Akt such as mTOR, GSK3, CREB as well as FOXO play a role in cognitive function. Insulin stimulated phosphorylation of Akt also affects the translocation of the insulin-sensitive glucose transporter GLUT4 to the plasma membrane. In addition to the PI3K/Akt cascade above, insulin activates the MAPK pathways. Anti-diabetic agents boosting insulin signaling exhibit promising pro-cognitive effects. Metformin inhibits mitochondrial complex I, thereby increasing AMP/ATP ratio and activating AMPK to protect neurons from oxidative stress. Metformin also upregulates the expression of BDNF via the activation of AMPK and CREB. GLP-1 agonists increase CAMP levels followed by activating PI3K/Akt signaling and PKA signaling pathways. Pioglitazone and rosiglitazone activate PPAR $\gamma$, resulting in gene transcription and neuroprotective effects. Sulforaphane exhibits promising neuroprotective effects which is known for an activator of Nrf2-antioxidant response element pathway. Quercetin also enhances cognitive function through its AMPK activity and modulating Akt signaling. IRS: insulin receptor substrate; PI3K: phosphoinositide 3-kinase; Akt: protein kinase B; CREB: CAMP response element binding protein; FOXO: forkhead box transcription factors of the class O; mTOR: mammalian target of rapamycin kinase; GSK3: glycogen synthase kinase 3; GLUT: glucose transporter; MAPK: mitogenactivated protein kinase; AMPK: AMP-activated protein kinase; GLP: glucagon-like peptide; PKA: protein kinase A; VGCCs: voltage gated calcium channels; PPAR: peroxisome proliferator-activated receptors.

\section{Preclinical Studies}

Fourteen consecutive days of intranasal insulin treatment could prevent the severe memory and learning impairment induced by intracerebroventricular administration of $A \beta$, which was a rat model of $\mathrm{AD}$ (Farzampour et al., 2016). In transgenic mouse model of $\mathrm{AD}$, intranasal insulin improved cognitive impairment through promotion of neurogenesis, alleviation of $\mathrm{A} \beta$ pathology and enhancement of insulin signaling(Mao et al., 2016). Intranasal delivery of insulin for 7 days restored insulin signaling, increased synaptic protein expression and reduced $A \beta$ levels and microglial activation in the brains of $\mathrm{AD}$ mouse model(Chen et al., 2014). These studies suggested that the beneficial effects of intranasal insulin on cognitive deficits could be partially due to the enhancement of insulin signaling and synaptic plasticity and the reduction of $A \beta$ level and neuroinflammation in the brain.

\section{Clinical Studies}

In healthy subjects, intranasal intake of insulin improved consolidation of words and general mood, indicating intranasal insulin as a potential treatment in patients showing cognitive deficits in conjunction with a lack of insulin(Benedict et al., 2004). Acute administration of intranasal insulin enhanced functional connectivity between the dorsal medial prefrontal cortex of the default-mode network and the hippocampus in healthy lean, overweight and obese adults, although this study missed examination on cognitive function(Kullmann et al., 2017).

Previous research studies have evaluated the cognitive beneficial effect of intranasal insulin therapy in nonschizophrenia patients. Adjunctive intranasal insulin administration was safe, well tolerated, and effective on a measure of executive function in bipolar disorder(McIntyre et al., 2012). Systematic reviews also suggested that intranasal insulin administration might have a beneficial effect on cognitive function in amnestic mild cognitive impairment and $\mathrm{AD}$ (Lu and $\mathrm{Xu}, 2019$ ), probably modified by apolipoprotein (APOE) 4 allele carrier status(Avgerinos et al., 2018). A pilot clinical trial demonstrated that 4 months intranasal insulin treatment stabilized or improved cognition, function and cerebral glucose metabolism for adults with amnestic mild cognitive impairment and $\mathrm{AD}$ (Craft et al., 2012). Other studies showed sex and APOE 


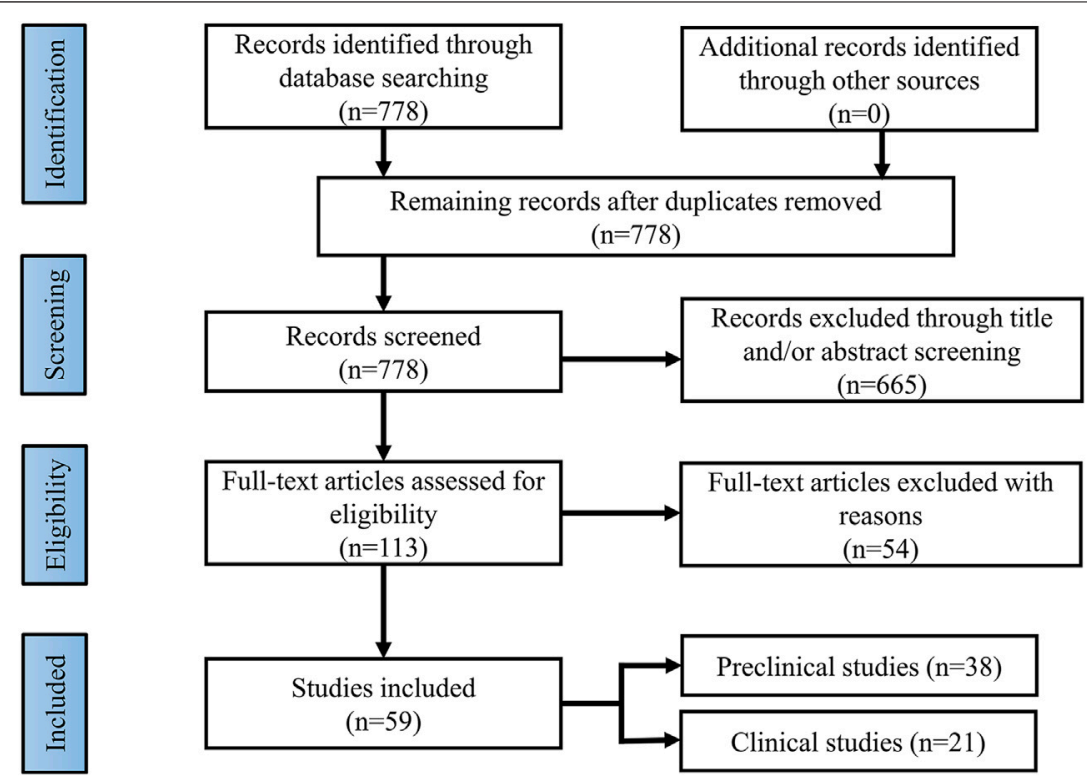

FIGURE 3 | Flowchart of study selection

genotype differences in treatment response to different doses of intranasal insulin in adults with mild cognitive impairment or $\mathrm{AD}$ (Reger et al., 2008; Claxton et al., 2013). There may be a fundamental difference in central insulin sensitivity in sex and APOE genotype differences(Claxton et al., 2013). Long acting intranasal insulin detemir also provided cognitive benefit for individuals diagnosed with mild cognitive impairment and $\mathrm{AD}$ dementia, and in particular for memory-impaired adults who were APOE- $\varepsilon 4$ carriers(Claxton et al., 2015). More recently, a randomized clinical trial demonstrated that insulin modulated aspects of brain function relevant to $\mathrm{AD}$ and could be delivered into the brain using intranasal devices, although this study failed to confirm the cognitive benefit of intranasal insulin(Craft et al., 2020). A clinical trial did not demonstrate statistically significant improvements on overall mood, aspects of emotional processing, neurocognitive function, or self-reported quality of life patient reported outcomes in major depressive disorder either(Cha et al., 2017).

The cognitive benefit of intranasal insulin in healthy subjects and AD may not generalize to schizophrenia. Single-dose intranasal insulin treatment (40 IU) did not have significant beneficial effect on verbal memory and sustained attention in patients with schizophrenia(Fan et al., 2011). This trial excluded diabetic patients and the negative findings might be explained by the small sample size, the dosing of insulin, the severity of baseline cognitive deficits in study subjects and the timing of posttreatment cognitive assessment(Fan et al., 2011). Another 8week clinical trial also failed to demonstrate any significant beneficial effect of intranasal insulin on cognition in patients with schizophrenia(Fan et al., 2013). Likewise, there were no significant differences in body metabolism between the adjunctive therapy of intranasal insulin (40 IU 4 times per day) group and the placebo group for schizophrenia patients
(Li et al., 2013). However, these studies excluded diabetes mellitus subjects and it was possible that the adjunctive intranasal insulin treatment was not able to mitigate the side effect of antipsychotic treatment that patients received before(Fan et al., 2013; Li et al., 2013). Another challenge is the uncertainty of how efficient the drug is delivered into the brain via intranasal insulin. Larger sample size and multi-site studies considering dose, course and nasal-tobrain insulin delivery efficiency are expected to investigate whether intranasal insulin treatment shows beneficial effect in schizophrenia patients with cognitive deficits.

\section{Metformin}

Metformin, a biguanide anti-diabetic drug, is recommended as first line treatment in T2DM. The main effect of metformin is to acutely decrease hepatic glucose production through the inhibition of mitochondrial respiratory chain complex I and subsequent the activation of AMPK(Viollet et al., 2011). Metformin is also known to have numerous nonglycemic effects. Metformin could activate AMPK pathway to protect neurons from oxidative injury(Zhao et al., 2019), produce antidepressant effects(Fang et al., 2020), and prevent neuroinflammation and neurodegeneration (Paudel et al., 2020).

\section{Preclinical Studies}

Chronic hyperinsulinemia in Neuro2a cells leaded to reduction of phosphorylation of IRS-1, PI3K, translocation of glucose transporter (GLUT) 4 and expression of GLUT3, and metformin could directly reverse such neuron insulin resistance status(Gupta et al., 2011). Metformin protected rats against from methamphetamine-induced neurodegeneration via the modulation of Akt/GSK3 or CREB/BDNF signaling pathway, and the amelioration of behavioral changes such as anxiety, depression and cognitive deficits(Keshavarzi et al., 2019). 
TABLE 1 | Preclinical studies: targeting insulin pathway to improve cognitive deficits

\begin{tabular}{|c|c|c|c|c|}
\hline Refs & Drug & $\begin{array}{l}\text { In vitro/vivo models, } \\
\text { dose used, and } \\
\text { intervention period }\end{array}$ & $\begin{array}{l}\text { Key Findings } \\
\text { i: Biochemical test; } \\
\text { ii: Gene and protein } \\
\text { expression analysis; } \\
\text { iii: Immunohistochemistry and } \\
\text { image analysis; } \\
\text { iv: Electrophysiology analysis; } \\
\text { v: Behavioural assessment; }\end{array}$ & Brief Conclusions \\
\hline
\end{tabular}

\begin{tabular}{|c|c|c|}
\hline $\begin{array}{l}\text { Farzampour et al. } \\
(2016)\end{array}$ & Intranasal insulin & $\begin{array}{l}A \beta \text {-induced rat model of } A D \text { received } \\
\text { normal saline or insulin }(0.1,0.2 \text {, and } \\
0.3 U) \text { for } 14 \text { consecutive davs }\end{array}$ \\
\hline Chen et al. (2014) & Intranasal insulin & $\begin{array}{l}\text { 9-month-old 3xTg-AD mice received } \\
\text { intranasal insulin } 1.75 \mathrm{U} / 17.5 \mu \mathrm{l} \text { or } \\
\text { vehicle for } 7 \text { days. }\end{array}$ \\
\hline
\end{tabular}

Mao et al. (2016) Intranasal insulin APP/PS1 mice received intranasal insulin $1 \mathrm{U} /$ day or vehicle for 6 weeks.
Gupta et al. (2011) Metformin

Keshavarzi et al. Metformin

(2019)

Ou et al. (2018) Metformin

Metformin v: (0.2 and 0.3 IU) $\uparrow$ working and reference memory: MWM;

ii: restored the insulin signaling in the brain: IR, IGF-1R, IRS-1, PI3K, PDK1 and AKT; $\uparrow$ the level of synaptic proteins: synapsin1, PSD95, synaptophysin; $\downarrow$ A $\beta 40$ level and microglia activation;

ii: improved aberrant insulin signaling in the brain : IR $\beta$, IGF1R, IRS1, PDK1, AKT; $\downarrow$ the activation of JNK;

iii: $\downarrow$ the area of $A \beta$ plaque in the brain; $\uparrow$ the number of doublecortin-immunoreactive cells;

v: $\downarrow$ anxiety and $\uparrow$ spatial learning and memory function: OFT, MWM;

i: $\uparrow$ glucose uptake: $\uparrow$ 2-DOG uptake (maximum $1.6 \mathrm{mM}$ );

Neuro-2a cells exposed to hyperinsulinemic condition before treatment with metformin (0-3.2 mM) for $24 \mathrm{~h}$ or $48 \mathrm{~h}$.

ii: $\uparrow$ phosphorylation of IR $\beta$, IRS1, PI3K, Akt (1.6 mM); $\downarrow$ tau phosphorylation, tau kinase, GSK3 $\beta$, ERK 1/2, FAK phosphorylation, amyloid- $\beta ; \uparrow$ insulin-stimulated PKC $\zeta$ phosphorylation; $\downarrow$ Ache activity; $\downarrow N F-\kappa B$ translocation to the nucleus; $\uparrow$ AMPK phosphorylation (1.6 mM);

In methamphetamine treated rats i: $\downarrow$ the activity of antioxidant enzymes: SOD, GPx and GR $(75,100,150 \mathrm{mg} / \mathrm{kg})$ ii: $\uparrow$ CREB, BDNF expression/level (75, 100, $150 \mathrm{mg} / \mathrm{kg}), \uparrow$ Akt expression and inhibited GSK3 expression/level (100, 150 mg/kg), $\downarrow$ the level of inflammatory biomarkers: TNF- $\alpha$ and IL-1 $\beta(100,150 \mathrm{mg} / \mathrm{kg})$ in the hippocampus;

v: protected rats from anxiety, depression, cognition impairment and motor activity disturbances: OFT, FST, EPM, TST, OFT, MWM;

In APP/PS1 mice:

APP/PS1 female mice received $200 \mathrm{mg} / \mathrm{kg}$ metformin i.p. for 14 days and wild type littermates were injected with saline.

ii: $\downarrow$ brain $A \beta$ deposition and $A \beta$ levels; $\downarrow$ inflammatory cytokine levels (IL-1 $\beta$ and TNF- $\alpha$ ); $\uparrow$ the levels of AMPK, $\downarrow$ p-mTOR, p-S6K, p-P65NFkB and BACE 1; iii: $\downarrow$ neuronal cell death, $\uparrow$ neurogenesis, $\downarrow$ inflammatory reaction (astrocytic and microglia reactivity);

v: rescued spatial memory deficits: MWM; In APP/PS1 mice

7-month-old male APP/PS1 mice (C57BL/6) received (200 mg/kg p.o.) metformin for 8 weeks. i: $\downarrow$ brain oxidative stress and inflammation: MDA and SOD; IL-1 $\beta$ and IL-6; ii: $\downarrow$ brain $A \beta$ accumulation; $\uparrow$ insulindegrading enzyme, neprilysin, and p-AMPK expression;

iii: $\uparrow$ brain function: $\uparrow 18 \mathrm{~F}$ -

Fluordeoxyglucose uptake (microPET-CT); v: ameliorated learning and memory dysfunction: MWM and Y-maze tests;
Intranasal insulin treatment improved memory and learning in a rat amyloidbeta model of Alzheimer's disease. Daily intranasal insulin into 3xTg-AD mice for 7 days restored insulin signaling, increased synaptic proteins, and reduced $A \beta 40$ level and microglia activation in the brain.

Intranasal insulin treatment for 6 weeks could decrease anxiety-related behaviors, ameliorate cognitive deficits, enhance the impaired brain insulin signaling, alleviate of $A \beta$ pathology and promote neurogenesis.

Metformin ameliorated neuronal insulin resistance and $A D$-neuropathological changes; activated AMPK.

Metformin protected the brain against from methamphetamine-induced neurodegeneration through mediating CREB/BDNF or Akt/GSK3 signaling pathway.

Metformin could alleviate amyloidogenesis and inflammatory responses, and improve spatial memory, neuroprotection, neurogenesis of the hippocampus in APP/PS1 mice.

Metformin could relieve learning and memory dysfunction and improve brain function in APP/PS1 mice.

(Continued on following page) 
TABLE 1 | (Continued) Preclinical studies: targeting insulin pathway to improve cognitive deficits

$\begin{array}{ll}\text { Refs Drug } & \begin{array}{l}\text { In vitro/vivo models, } \\ \text { dose used, and } \\ \text { intervention period }\end{array}\end{array}$

Wang et al. (2020) Metformin

Wang et al. (2019) Metformin

\section{Chen et al. (2012) GLP-1 or} exendin-4

Zhou et al. (2019)

Dulaglutide

Batista et al. (2018)

Liraglutide

McClean et al. (2011) Liraglutide
SAMP8 mouse received daily injections of metformin at $20 \mathrm{mg} / \mathrm{kg}$ sc or $200 \mathrm{mg} / \mathrm{kg} / \mathrm{sc}$ for 8 weeks.

APP/PS1 mouse were injected intraperitoneally with metformin (200 mg/kg/day) or saline for 10 days.

Male SD rats received normal saline or MK-801 $(0.1 \mathrm{mg} / \mathrm{kg}$, twice-daily, i.p., 2 weeks) and then the MK-801 group randomly received vehicle, metformin $(300 \mathrm{mg} / \mathrm{kg}$ ) or olanzapine (4 mg/kg), i.p., for 4 weeks.

PC12 cells were treated with high glucose or hydrogen peroxide for $96 \mathrm{~h}$ before treatment with GLP-1 or exendin-4 (50, 100, 200, and 1,000 $\mathrm{nM})$ for $96 \mathrm{~h}$.

STZ-induced AD-like mice or contro mice received vehicle, dulaglutide (0.6 mg/kg/week i.p.), or dulaglutide and exendin (9-39) $(0.67 \mathrm{mg} / \mathrm{kg} /$ week i.p.) for 4 weeks.

Male Swiss mice received daily i.p. injections of liraglutide ( $25 \mathrm{nmol} / \mathrm{kg}$ ) or vehicle (PBS) for 7 days before received the injection of $A \beta$ oligomers $(A \beta O)$ (10 pmol) or vehicle into the lateral ventricle; Four $A \beta O$-injected non-human primates, two $A \beta$ O-injected non-human primates that received liraglutide treatment and three controls.

7-month-old APP/PS1 mice and wild type controls received saline or liraglutide $(25 \mathrm{nmol} / \mathrm{kg}$ body weight i.p. once daily) for 8 weeks.

\section{Key Findings \\ i: Biochemical test; \\ ii: Gene and protein \\ expression analysis; \\ iii: Immunohistochemistry and \\ image analysis; \\ iv: Electrophysiology analysis; \\ v: Behavioural assessment;}

In SAMP8 mouse:

i: $\uparrow$ PKC $(20 \mathrm{mg} / \mathrm{kg})$;

ii: $\uparrow$ pGSK-3 $\beta$ ser $(200 \mathrm{mg} / \mathrm{kg}) ; \downarrow A \beta$ (20 mg/kg); $\downarrow$ pTau and APPc99 (20 and $200 \mathrm{mg} / \mathrm{kg}$ );

v: $\uparrow$ learning and memory: T-maze and NOR;

ii: prevented Cdk5 hyperactivation ( $\downarrow$ phosphorylation level of histone $\mathrm{H} 1$ ); inhibited cleavage of p35 into p25; iii: corrected the dendritic spine density to control level; rescued AMPA submit GluA1 expression;

iv: reversed the decreased $f$ EPSP inputoutput; rescued LTP defects;

v: rescued spatial memory deficits: MWM; ii: (metformin) $\downarrow$ the MK-801 induced higher phosphorylation of Akt and GSK3 $\beta$; v: (metformin or olanzapine) alleviated MK801 induced PPI deficits, hyperactivity

(OFT), cognition memory and spatial learning deficits (MWM); (metformin) alleviated MK-801 induced anxiety like behaviors (elevated plus maze test); 100 nM GLP-1 or exendin-4

ii: $\downarrow$ the elevated $\mathrm{Bax} / \mathrm{Bcl}-2$ ratio in high glucose-induced neurotoxicity;

iii: $\uparrow$ cell viability in $\mathrm{H}_{2} \mathrm{O}_{2}$ triggered cytotoxicity;

i: no effects on blood glucose; dulaglutide $\downarrow$ body weight;

ii: dulaglutide $\downarrow$ the phosphorylation levels of tau and neurofilaments; dulaglutide $\uparrow$ the expression of GLP-1 and GLP-1R expression; dulaglutide $\uparrow$ PI3K/AKT/GSK3 $\beta$ pathway in the STZ mice brain;

v: dulaglutide $\uparrow$ learning and memory impairment of AD-like mice: MWM;

In $A \beta$ O-injected mice:

ii: $\uparrow$ PKA activity; preserved hippocampal level of IRa mRNA;

v: prevented memory impairment: NOR, the object location memory test;

In $A \beta$ O-injected non-human primates: ii: $\uparrow \mathrm{IR} \alpha$ and IR $\beta$ in the frontal cortex; $\uparrow$ IR $\alpha$ in the hippocampus; attenuated $A \beta$ O-induced AD-like tau phosphorylation; iii: $\uparrow$ synaptosin, PSD 95 and density of synapse in the hippocampus, frontal cortex and amygdala;

In APP/PS1 mice:

iii: $\downarrow A \beta$ formation; $\downarrow$ microglia activation; $\uparrow$ synaptophysin levels; $\downarrow A \beta$ oligomer and total brain APP levels;

iv: $\uparrow$ induction and maintenance of LTP; v: prevented memory impairment: object recognition; MWM;

\section{Brief Conclusions}

Metformin at 20 and $200 \mathrm{mg} / \mathrm{kg}$ improved memory in 12-month-old SAMP8 mice.

Metformin could inhibit Cdk5 activity to restore spine density, surface GluA1 trafficking, LTP expression and spatial memory to those of normal level in the APP/PS1 mice.

Metformin reversed MK-801 induced schizophrenia-like symptoms (PPI deficits, hyperactivity, anxiety-like symptoms, recognition and spatial memory impairment).

GLP-1 and exendin-4 inhibited high glucose-induced apoptosis and oxidative stress in neurons.

Dulaglutide ameliorated STZ-induced AD-like impairment of learning and memory ability by modulating hyperphosphorylation of tau and neurofilaments through PI3K/AKT/ GSK3 $\beta$ signaling pathway.

Liraglutide reversed cognitive impairment and IR loss caused by $\mathrm{A} \beta \mathrm{O}$ in mice, and it also exerted partial neuroprotective actions in non-human primates.

Liraglutide prevented neurodegenerative development in a mouse model of $A D$. 
TABLE 1 | (Continued) Preclinical studies: targeting insulin pathway to improve cognitive deficits

$\begin{array}{ll}\text { Refs Drug } & \begin{array}{l}\text { In vitro/vivo models, } \\ \text { dose used, and } \\ \text { intervention period }\end{array}\end{array}$

Hansen et al. (2015) Liraglutide

McClean et al. (2015) Liraglutide

Duarte et al. (2020) Liraglutide

Robinson et al. (2019) Insulin combination with intranasal administration of insulin and exenatide

Bomba et al. (2018) Exenatide daily for 4 months. 6-month-old senescenceaccelerated mouse prone 8 (SAMP8) mice received liraglutide (100 or $500 \mathrm{ug} / \mathrm{kg} /$ day, s.c.) or vehicle once

2-months-old APP/PS1 mice received liraglutide $(25 \mathrm{~nm} / \mathrm{kg}$ bw i.p.) or vehicle for 8 months.

10-month-old 3xTg-AD female mice received liraglutide $(0.2 \mathrm{mg} / \mathrm{kg}$, once/ day) for 28 days. exenatide $\left(0.43 \times 10^{-3} \mathrm{IU}+0.075 \mu \mathrm{g}\right.$ exenatide $+5 \mu \mathrm{g}$ BSA per mouse once daily).

10 months age adult mice received exenatide (500 mg/kg, bw, i.p.) or vehicle 5 days per week for 2 months.

\section{Key Findings \\ i: Biochemical test; \\ ii: Gene and protein \\ expression analysis; \\ iii: Immunohistochemistry and \\ image analysis; \\ iv: Electrophysiology analysis; \\ v: Behavioural assessment;}

i: no effects on blood sugar levels;

iii: $\downarrow$ hyperphosphorylation of

neurofilaments in the brain; $\downarrow$

hyperphosphorylated tau in the brain; $\uparrow$

microtubule binding tau impaired by STZ;

ameliorated ERK and JNK signaling;

$\mathrm{v}: \uparrow$ learning and memory

impairment: MWM;

In SAMP8 mice:

i: no effects on body wight, food intake;

iii: preserved hippocampal CA1 pyramida

neurons;

$\mathrm{v}: \uparrow$ memory retention: active-avoidance

T-maze task; no effects on NOR tests;

In APP/PS1 mice:

i: no effects on body wight and plasma

glucose;

iii: $\downarrow$ plaque load and inflammatory response (microglia activation); $\uparrow$ synaptophysin

levels;

iv: $\uparrow$ LTP;

$\mathrm{v}: \uparrow$ cognition: MWM; maintained

recognition memory: NOR; no effects on

the open field tests;

In 3xTg-AD mice:

i: normalized plasma inflammatory markers; promoted brain glucose metabolism;

ii: $\downarrow$ brain $A \beta_{1-42}, A \beta_{1-40}$ and $p$-tau; partly normalized brain levels of estradiol and

GLP-1-related signaling; rescued brain

oxidative/nitrosative stress markers;

v: limited signs of cognitive changes: MWM;

The combination of insulin and exenatide:

ii: normalized expression of insulin receptor pathway genes; no effects on $A \beta$ levels;

$\mathrm{v}: \uparrow$ spatial learning but did not reach significance: MWM;

i: no effects on body wight, fasting glycemia; ii: $\uparrow$ expression of BDNF and

phosphorylation of BDNF, TrkB, ERK5 and

PSD95 in the hippocampus; $\downarrow$ the expression of pro BDNF, p75NTR, and phosphorylated ERK1,2 (pERK1,2) and JNK ( $p$ JNK);

iii: $\uparrow$ dendritic spine density in hippocampal neurons;

$\mathrm{v}: \uparrow$ long-term memory

performance: MWM;

In 5XFAD mice:

5-month-old male 5xFAD transgenic $A D$ mice received exenatide s.c. for 16 weeks (100 ug/kg twice per day).
Exenatide ii: $\downarrow$ MDA level and $\uparrow$ SOD activity; $\uparrow$ ATP level and respiratory chain complex lactivity;

iii: $\downarrow A \beta$ deposition in the hippocampal CA1 region; alleviated synaptic degradation in the hippocampus; $\uparrow$ mitochondrial morphology in the hippocampus; normalized mitochondrial dynamics; v: $\uparrow$ learning ability and spatial memory ability: MWM;

\section{Brief Conclusions}

Liraglutide exhibited neuroprotection effects on STZ-induced AD-like memory and learning impairment mice by modulating the hyperphosphorylation of tau and neurofilament proteins and insulin signaling.

Liraglutide delayed or partially halted the progressive decline in memory function associated with hippocampal neuronal loss in SAMP8 mice.

Liraglutide reduced $A D$ progressive neurodegeneration in the APP/PS1 mouse model.

Liraglutide partially attenuated brain estradiol and GLP-1 and activated PKA levels, oxidative/nitrosative stress and inflammation in these $A D$ female mice.

Combination of insulin with exenatide was associated with better memory and normal expression of insulin receptor pathway genes in a mouse model of $A D$.

Exenatide improved age-dependent cognitive decline through promoting the BDNF-TrkB neurotrophic axis and inhibiting apoptosis by activating decreasing p75NTR-mediated signaling.

Exenatide treatment could improve cognitive impairment, reduce $A \beta_{1-42}$ deposition, alleviate synaptic degradation, improve mitochondrial morphology, relieve oxidative stress, correct the crisis of mitochondrial energy production and normalize mitochondrial morphology in 5xFAD transgenic $A D$ mice.

(Continued on following page) 
TABLE 1 | (Continued) Preclinical studies: targeting insulin pathway to improve cognitive deficits

\begin{tabular}{|c|c|c|c|c|}
\hline Refs & Drug & $\begin{array}{l}\text { In vitro/vivo models, } \\
\text { dose used, and } \\
\text { intervention period }\end{array}$ & $\begin{array}{l}\text { Key Findings } \\
\text { i: Biochemical test; } \\
\text { ii: Gene and protein } \\
\text { expression analysis; } \\
\text { iii: Immunohistochemistry and } \\
\text { image analysis; } \\
\text { iv: Electrophysiology analysis; } \\
\text { v: Behavioural assessment; }\end{array}$ & Brief Conclusions \\
\hline
\end{tabular}

\begin{tabular}{|c|c|c|}
\hline Bomba et al. (2019) & Exenatide & $\begin{array}{l}\text { 6-month-old } 3 \times T \text { T-AD mice rece } \\
\text { control or HFD before treatment } \\
\text { exenatide ( } 500 \text { ug/kg body weig } \\
\text { i.p., } 5 \text { days per week) or vehicle } \\
3 \text { months. }\end{array}$ \\
\hline Chen et al. (2019b) & $\begin{array}{l}\text { Sitagliptin and } \\
\text { saxagliptin }\end{array}$ & $\begin{array}{l}\text { 3xTg mice received sitagliptin } \\
(3.5 \mathrm{mg} / \mathrm{kg} \text { s.c.) and saxagliptin } \\
(2.6 \mathrm{mg} / \mathrm{kg} \text { s.c.) for } 56 \text { days. }\end{array}$ \\
\hline
\end{tabular}

Kosaraju et al. (2013a) Saxagliptin

Kosaraju et al. Vildagliptin (2013b)

Kosaraju et al. (2017) Linagliptin

Babic et al. (2018) Liraglutide

Jantrapirom et al. Liraglutide (2020) $1 \mathrm{mg} / \mathrm{kg}$ p.o.) for 60 days $10 \mathrm{mg} / \mathrm{kg}$ p.o.) for 30 days.

SD rats were randomly treated with olanzapine (2 mg, tid), clozapine tid), olanzapine + liraglutide cotreatment or vehicle for 6 weeks.

\section{In 3xTg-AD mice HFD mice:}

i: no effects on body wight, glucose

metabolism;

ii: no effects on the levels of $A \beta$ and tau; $\uparrow$ the level of BDNF, pERK5, pCREB, pSyn, PSD95 and pTrkB; reverted the HFDinduced activation of proBDNF/p75NTR signaling;

v: no effects on learning and memory

function: MWM;

In 3xTg-AD mice HFD mice:

ii: $\uparrow$ the level of GLP-1 and GLP-1R in the brain; $\uparrow$ the synapse protein level and activated CREB; modulated the phosphorylation and O-Glycosylation of tau and neurofilaments protein; $\uparrow$ GLP-1 signaling;

$\mathrm{v}: \uparrow$ spatial learning and memory ability: MWM;

Streptozotocin-induced rat model of AD received saxagliptin $(0.25,0.5$ and

i: $\uparrow$ the level of GLP-1;

ii: $\downarrow A \beta_{1-42}$ in the hippocampus; $\downarrow$ total tau and $p$-tau in the hippocampus; $\downarrow$ the level of TNF- $\alpha$ and IL- $1 \beta$ in the hippocampus; iii: $\uparrow$ cresyl violet-positive neurons in the hippocampus;

$\mathrm{v}$ : $\uparrow$ learning and memory: radial arm maze task; hole-board task;

Streptozotocin-induced rat model of AD received vildagliptin $(2.5,5$ and

ii: $\uparrow$ the level of GLP- $1 ; \downarrow A \beta_{42}$ in the brain; $\downarrow$ $p$-tau in the brain; $\downarrow$ the level of TNF- $\alpha$ and IL- $1 \beta$ in the brain;

iii: $\uparrow$ cresyl violet-positive neurons in the brain;

$\mathrm{v}$ : $\uparrow$ learning and memory: radial arm maze task; hole-board task;

$\mathrm{i}: \uparrow$ the level of GLP-1 and GIP in the brain but had no effect on plasma glucose level; ii: $\downarrow A \beta_{42}$ in the brain; $\downarrow p$-tau in the brain; $\downarrow$ neuroinflammation;

iii: $\downarrow$ thioflavin S positive plaques in the brain; v: $\uparrow$ cognitive performance: MWM; Y-maze; i: $\uparrow$ clozapine-induced glucose intolerance; $\downarrow$ olanzapine-induced weight gain, (12 mg/kg, tid), liraglutide $(0.2 \mathrm{mg} / \mathrm{kg}$, treatment, clozapine + liraglutide co-

diposity;

v: prevented olanzapine- and clozapine-

induced deficits in recognition memory: $\downarrow$ the NOR test discrimination ratio; partially reversed olanzapine-induced working memory (T-Maze test) and voluntary locomotor activity deficits;

ii: $\uparrow$ the phosphorylation of IR, IRS-1, Akt and GSK3 $\beta$; $\downarrow$ the formation of Alzheimer's markers and plaque (amyloid plaque and tau phosphorylation); $\downarrow$ BACE-1 activity in insulin resistant neurons;

Exenatide reverted the adverse changes of BDNF signaling and neuroinflammation status of 3xTg-AD mice undergoing HFD without affecting systemic metabolism or promoting changes in cognitive performances.

DPP-4 inhibitors improved the impaired spatial learning and memory, decreased tau and NFs aggregation, increased $A \beta$ degradation and reversed $\mathrm{AD}$-like neurodegeneration through partial improvement of GLP-1 signaling pathway including PI3K-Akt and MAPK.

Saxagliptin attenuated $A \beta$ burden, tau phosphorylation, inflammation and reversed behavioural deficits in streptozotocin-induced rat model of $A D$.

Vildagliptin exhibited improvement memory retention and attenuation of $A \beta$, tau phosphorylation and inflammatory markers and increased GLP-1 level.

Linagliptin, a dipeptidyl peptidase-4 inhibitor, mitigates cognitive deficits and pathology in the 3xTg-AD mouse model of $A D$.

Liraglutide co-treatment improved aspects of cognition, prevented obesity side effects of olanzapine, and the hyperglycemia caused by clozapine.

Liraglutide restored neuronal insulin

resistance and ameliorated AD markers. without high level of insulin (100 nM) for $48 \mathrm{~h}$ before treatment with liraglutide $(500 \mathrm{nM})$ for $24 \mathrm{~h}$
(Continued on following page) 
TABLE 1 | (Continued) Preclinical studies: targeting insulin pathway to improve cognitive deficits

\begin{tabular}{|c|c|c|c|}
\hline Refs & Drug & $\begin{array}{l}\text { In vitro/vivo models, } \\
\text { dose used, and } \\
\text { intervention period }\end{array}$ & $\begin{array}{l}\text { Key Findings } \\
\text { i: Biochemical test; } \\
\text { ii: Gene and protein } \\
\text { expression analysis; } \\
\text { iii: Immunohistochemistry and } \\
\text { image analysis; } \\
\text { iv: Electrophysiology analysis; } \\
\text { v: Behavioural assessment; }\end{array}$ \\
\hline Gad et al. (2016) & $\begin{array}{l}\text { Pioglitazone and } \\
\text { exenatide }\end{array}$ & $\begin{array}{l}\text { Male Wistar albino rats received } \\
\text { fructose to induce insulin resistance } \\
\text { before treatment with pioglitazone } \\
(10 \mathrm{mg} / \mathrm{kg} \text { ), exenatide ( } 10 \text { or } \\
20 \mu \mathrm{g} / \mathrm{kg} \text { ), pioglitazone plus } \\
\text { exenatide or vehicle for } 8 \text { weeks. }\end{array}$ & $\begin{array}{l}\text { Monotherapy or combination of } \\
\text { pioglitazone and exenatide } \\
\text { i: } \downarrow \text { blood glucose levels, insulin level and } \\
\text { HOMA-IR index; } \downarrow \text { serum advanced } \\
\text { glycated end products; } \downarrow \text { serum lipids: TG, } \\
\text { TG, LDL levels; } \\
\text { iii: } \downarrow \text { percent of hippocampal pycnotic cells; } \\
\downarrow \text { hippocampal A } \beta \text { expression; } \downarrow \\
\text { hippocampal microglia expression; } \\
\text { v: } \uparrow \text { cognition: eight-arm radial maze test; }\end{array}$ \\
\hline Chen et al. (2015) & Pioglitazone & $\begin{array}{l}\text { 12-month-old APP/PS1 mice } \\
\text { received pioglitazone i.p. (10 mg/kg/ } \\
\text { day) for } 15 \text { days. }\end{array}$ & $\begin{array}{l}\text { In AD mouse model: } \\
\text { ii: } \downarrow \text { Cdk5 activity by decreasing p35 protein } \\
\text { level; } \\
\text { iii: reversed } A \beta \text {-induced dendritic spine } \\
\text { loss; } \\
\text { iv: rescued LTP defects; } \\
\text { v: } \uparrow \text { spatial memory: MWM; }\end{array}$ \\
\hline Yu et al. (2015) & $\begin{array}{l}\text { pioglitazone or } \\
\text { rosiglitazone }\end{array}$ & $\begin{array}{l}3 \times T g-A D \text { mice and wild type control } \\
\text { mice received an experimental diet } \\
\text { containing pioglitazone hydrochloride } \\
\text { or rosiglitazone maleate for } 4 \text { months. }\end{array}$ & $\begin{array}{l}\text { In } 3 \times T g-A D \text { mice } \\
\text { i: pioglitazone and rosiglitazone: } \downarrow \text { the body } \\
\text { weight; } \\
\text { iii: pioglitazone and rosiglitazone: } \downarrow \text { tau } \\
\text { phosphorylation in the hippocampus; } \uparrow \\
\text { AKT signaling in the brain; } \downarrow \\
\text { neuroinflammation; } \\
\text { v: pioglitazone improved learning } \\
\text { ability: MWM; }\end{array}$ \\
\hline Escribano et al. (2010) & Rosiglitazone & $\begin{array}{l}\text { 9-month-old transgenic mice } \\
\text { overexpressing human amyloid } \\
\text { precursor protein (hAPP) received } \\
\text { rosiglitazone p.o. } 5 \mathrm{mg} / \mathrm{kg} / \text { day for } \\
4 \text { weeks. }\end{array}$ & $\begin{array}{l}\text { ii: } \downarrow \text { brain } A \beta \text { levels and } A \beta \text { plaque } \\
\text { deposition; } \downarrow p \text {-Tau aggregates; } \\
\text { v: } \downarrow \text { memory deficits: object recognition } \\
\text { and MWM; }\end{array}$ \\
\hline $\begin{array}{l}\text { Sabogal-Guáqueta } \\
\text { et al. (2015) }\end{array}$ & Quercetin & $\begin{array}{l}3 x T g-A D \text { mice received quercetin } \\
\text { ( } 25 \mathrm{mg} / \mathrm{kg} \text { i.p.) or vehicle every } \\
48 \text { hours for } 3 \text { months. }\end{array}$ & $\begin{array}{l}\text { ii: } \downarrow \beta \text {-amyloidosis, } \beta \text { A } 1-40 \text { and } \beta \text { A } 1-42 \text { in } \\
\text { the brain; } \downarrow \text { tauopathy in the brain; } \downarrow \\
\text { astrogliosis and microgliosis in the brain; } \\
\text { iii: } \uparrow \text { the cell density in the subiculum; } \\
\text { v: } \uparrow \text { spatial learning and memory } \\
\text { performance: MWM; exerted anxiolytic } \\
\text { effect: EPM tests }\end{array}$ \\
\hline Wang et al. (2014) & Quercetin & $\begin{array}{l}\text { APPswe/PS1dE9 mice received } \\
\text { quercetin (20, } 40 \mathrm{mg} / \mathrm{kg} \text { bw, once } \\
\text { daily) or Aricept ( } 2 \mathrm{mg} / \mathrm{kg} \text { once daily) } \\
\text { or vehicle for } 16 \text { weeks. }\end{array}$ & $\begin{array}{l}\text { ii: } \downarrow \text { plaque pathology; attenuated } \\
\text { mitochondrial damage: mitochondrial } \\
\text { membrane potential, ATP levels; } \downarrow \text { ROS } \\
\text { production; } \uparrow \text { AMPK activity; } \\
\text { v: } \uparrow \text { recognition memory, learning and } \\
\text { memory function: novel object recognition } \\
\text { and MWM; }\end{array}$ \\
\hline Sriraksa et al. (2012) & Quercetin & $\begin{array}{l}\text { Male Wistar rats received quercetin } \\
\text { (100, } 200,300 \mathrm{mg} / \mathrm{kg} \text { bw, once daily) } \\
\text { orally or vehicle or levodopa or vitamin } \\
\mathrm{C} \text { for } 14 \text { days before and } 14 \text { days } \\
\text { after the unilateral lesion of right } \\
\text { substantia nigra induced by } 6-\mathrm{OHDA} \text {. }\end{array}$ & $\begin{array}{l}\text { ii: } \downarrow \text { Ache activity (300 mg/kg); } \downarrow \text { MDA levels } \\
\text { (300 mg/kg); } \uparrow \text { SOD, CAT and GPx activity } \\
\text { in the hippocampus ( } 300 \mathrm{mg} / \mathrm{kg}) \text {; } \\
\text { iii: } \uparrow \text { density of survival neuron in the } \\
\text { hippocampus; } \\
\text { v: } \uparrow \text { learning and memory: MWM; }\end{array}$ \\
\hline
\end{tabular}

Brief Conclusions

The combination of pioglitazone and exenatide offered hippocampal neuroprotection and produced procognitive effect in insulin resistant rats.

Pioglitazone inhibited Cdk5 activity by decreasing p35 protein level and rescued impaired synaptic plasticity and spatial memory in AD mouse models.

The chronic treatment of 3xTg-AD mice with pioglitazone or rosiglitazone for 4 months improved spatial learning and attenuated tau hyperphosphorylation and neuroinflammation.

Rosiglitazone reduced AD pathology and restored hippocampal function, leading to a rescue of memory impairment in APP transgenic mice.

Quercetin ameliorated cognitive deficits, reversed brain levels of $\beta$-amyloidosis and tauopathy and ameliorated astroglia and microglia reactivity in the $3 \times \mathrm{Tg}-\mathrm{AD}$ mice.

Quercetin ameliorated cognitive deficits reduced sensile plaques, and ameliorated mitochondrial dysfunction.

Quercetin enhanced spatial memory partly because of decreased oxidative damage resulting in decreased neuron density.

(Continued on following page) 
TABLE 1 | (Continued) Preclinical studies: targeting insulin pathway to improve cognitive deficits

\begin{tabular}{|c|c|c|c|c|}
\hline Refs & Drug & $\begin{array}{l}\text { In vitro/vivo models, } \\
\text { dose used, and } \\
\text { intervention period }\end{array}$ & $\begin{array}{l}\text { Key Findings } \\
\text { i: Biochemical test; } \\
\text { ii: Gene and protein } \\
\text { expression analysis; } \\
\text { iii: Immunohistochemistry and } \\
\text { image analysis; } \\
\text { iv: Electrophysiology analysis; } \\
\text { v: Behavioural assessment; }\end{array}$ & Brief Conclusions \\
\hline Mehta et al. (2017) & Quercetin & $\begin{array}{l}\text { Swiss albino mice were subjected to } \\
\text { an array of unpredicted stressors for } \\
21 \text { days during which } 30 \mathrm{mg} / \mathrm{kg} \\
\text { quercetin treatment was given orally. }\end{array}$ & $\begin{array}{l}\text { i: normalized chronic unpredicted stressors } \\
\text { mediated elevated blood glucose level, } \\
\text { elevated serum corticosterone level, serum } \\
\text { insulin and insulin sensitivity; } \\
\text { ii: } \uparrow \text { the expression of IR and GLUT4; } \\
\text { iii: alleviated chronic unpredicted stressors } \\
\text { mediated neuronal damage in hippocampus; } \\
\text { v: alleviated chronic unpredicted stressors } \\
\text { mediated cognitive dysfunction: } \\
\text { NOR, MWM; }\end{array}$ & $\begin{array}{l}\text { Quercetin improved chronic } \\
\text { unpredicted stressors mediated } \\
\text { cognitive dysfunction by modulating } \\
\text { hippocampal insulin signaling. }\end{array}$ \\
\hline Mert et al. (2019) & Quercetin & $\begin{array}{l}40 \text { Balb-C received corn oil + saline or } \\
\text { quercetin } 50 \mathrm{mg} / \mathrm{kg} / \text { day + saline or } \\
\text { corn oil + ketamine or quercetin } \\
25 \mathrm{mg} / \mathrm{kg} / \text { day+ ketamine or } \\
\text { quercetin } 50 \mathrm{mg} / \mathrm{kg} / \text { day + ketamine } \\
\text { for } 21 \text { days. }\end{array}$ & $\begin{array}{l}\text { ii: quercetin ( } 50 \mathrm{mg} / \mathrm{kg} \text { ) } \downarrow \text { the level of MDA } \uparrow \\
\text { the levels of GPx and SOD in both the } \\
\text { hippocampus and prefrontal cortex in } \\
\text { ketamine-administered mice; } \\
\text { v: improved ketamine induced cognitive } \\
\text { deficits; }\end{array}$ & $\begin{array}{l}\text { Quercetin improved ketamine induced } \\
\text { cognitive deficits in mice partly owing to } \\
\text { its ability to scavenge free radicals and } \\
\text { its high antioxidant capacity. }\end{array}$ \\
\hline Shirai et al. (2012) & Sulforaphane & $\begin{array}{l}\text { Male Std: ddy mice received } \\
\text { sulforaphane }(3,10 \text { and } 30 \mathrm{mg} / \mathrm{kg} \text {, } \\
\text { i.p.) after administration of PCP } \\
(3 \mathrm{mg} / \mathrm{kg} \text {, s.c.). }\end{array}$ & $\begin{array}{l}\text { v: Sulforaphane ( } 30 \mathrm{mg} / \mathrm{kg} \text {, i.p.) attenuated } \\
\text { hyperlocomotion in mice after PCP } \\
\text { administration; } \\
\text { Sulforaphane ( } 3,10 \text { and } 30 \mathrm{mg} / \mathrm{kg} \text {, i.p.) } \\
\text { attenuated PPI deficits in mice after PCP } \\
\text { administration; }\end{array}$ & $\begin{array}{l}\text { Sulforaphane attenuated } \\
\text { hyperlocomotion and PPI deficits in } \\
\text { mice after PCP administration in a dose- } \\
\text { dependent manner. }\end{array}$ \\
\hline Shirai et al. (2015) & Sulforaphane & $\begin{array}{l}\text { Schedule 1: male ICR mice received } \\
\text { vehicle + saline, or sulforaphane } \\
(30 \mathrm{mg} / \mathrm{kg} / \text { day, i.p. })+\text { saline, or } \\
\text { vehicle + PCP (10 mg/kg/day, s.c.) or } \\
\text { sulforaphane ( } 30 \mathrm{mg} / \mathrm{kg} / \text { day, i.p. })+ \\
\text { PCP (10 mg/kg/day, s.c.) for } \\
10 \text { days. Schedule } 2: \text { After schedule } \\
1 \text {, sulforaphane ( } 30 \mathrm{mg} / \mathrm{kg} / \text { day, i.p.) } \\
\text { or the vehicle was administered once } \\
\text { daily for } 14 \text { days. }\end{array}$ & $\begin{array}{l}\text { iii: schedule 1: pretreatment with } \\
\text { sulforaphane attenuated PCP-induced } \\
\text { reduction in the spine density, protected } \\
\text { against the PCP-induced increase in the 8- } \\
\text { oxo-dG-positive cells and decrease in PV- } \\
\text { positive cells in the mPFC and } \\
\text { hippocampus; } \\
\text { v: NOR: schedule 1: pretreatment with } \\
\text { sulforaphane attenuated PCP-induced } \\
\text { cognitive deficits in mice; } \\
\text { schedule 2: sulforaphane attenuated PCP- } \\
\text { induced cognitive deficits in mice; }\end{array}$ & $\begin{array}{l}\text { Sulforaphane had prophylactic and } \\
\text { therapeutic effects on PCP-induced } \\
\text { cognitive deficits in mice. }\end{array}$ \\
\hline
\end{tabular}

IGF1R: type 1 insulin-like growth factor receptor; PDK1: 3-phosphoinositide-dependent protein kinase-1; 2-DOG: [3H]2-deoxyglucose; AMPK: AMP activated protein kinase; IR: insulin receptor; IRS: insulin receptor substrate; PI3K: Phosphatidyl inositol 3-kinase; Akt: protein kinase B; GSK3: glycogen synthase kinase 3; ERK: extracellular regulated kinase; FAK: focal adhesion kinase; Ache: Acetylcholinesterase; NF-кB: nuclear factor kB; ROS: reactive oxygen species; OFT: Open Field Test; FST: forced Swim Test; EPM: Elevated Plus Maze; TST: Tail Suspension Test; MWM: Morris Water Maze; SOD: superoxide dismutase; CAT: catalase; GPx: superoxide dismutase; GR: glutathione reductase; TNF- $\alpha$ : tumor necrosis factor-alpha; IL1 $\beta$ : interleukine-1beta; CREB: cAMP response element binding protein; BDNF: brain-derived neurotrophic factor; PPI: pre-pulse intensity; ROS: reactive oxygen species; EGFR: Epidermal Growth Factor Receptor; Sirt1: silent information regulator 2 homolog 1; BACE-1: Beta Secretase 1; PS1: presenilin1; APP: amyloid precursor protein; NOR: Novel Object Recognition; RAGE: receptor for advanced glycation end products; ICV: intracerebroventricular; LA: L-arginine; L-NAME: nitro-L-arginine methyl ester; ORT: the object recognition test; STZ: streptozotocin; TrkB: tropomyosin-related kinase B receptor; p75NTR: p75 neurotrophin receptor; PAL: The passive avoidance learning; Mash1: Mammalian achaete-scute homologue 1; GIPR: gastric inhibitory polypeptide receptor; VEGF: vascular endothelial growth factor; T-AOC: total antioxidant capability; GSH: glutathione; GSHPx: Glutathione peroxidase; PCP: phencyclidine; RNS: reactive nitrogen species; Cdk5: Cyclin-dependent kinase 5.

Metformin attenuated spatial memory deficits, neuron loss in the hippocampus, decreased $\mathrm{A} \beta$ plaque load and chronic inflammation in the hippocampus and cortex, and enhanced neurogenesis in the APP/PS1 mice, mouse model of $\mathrm{AD}(\mathrm{Ou}$ et al., 2018; Chen et al., 2021). Metformin also restored spine density, surface AMPA subunit GluA1 trafficking, LTP expression and spatial memory in the APP/PS1 mouse by inhibiting cyclindependent kinase 5 hyper-activation and cyclin-dependent kinase 5-dependent tau hyperactivation(Wang et al., 2020). Furthermore, metformin could activate AMPK and insulin- degrading enzyme in the brain of APP/PS 1 mice, which might be the key neuroprotection mechanism of metformin(Lu et al., 2020). Metformin treatment for 8 weeks improved memory in the SAMP8 mouse model of sporadic AD, which was associated with the decreased levels of APPc99 and pTau404(Farr et al., 2019). In MK801-induced schizophrenia-like rats, metformin attenuated the olanzapine- and risperidoneinduced metabolic dysfunctions without reducing the therapeutic effects of the antipsychotics(Luo et al., 2020). Furthermore, in MK-801-induced schizophrenia-like models, 
metformin ameliorated the pre-pulse inhibition deficits, alleviated hyperactivity, the anxiety-like behaviors, recognition and spatial memory impairment through normalizing the phosphorylation of Akt and GSK3 $\beta$ in the cerebral cortex of rats(Wang et al., 2019).

\section{Clinical Studies}

At present, the relationship between metformin and cognitive performance is controversial in clinical studies. In patients with non-dementia vascular cognitive impairment and abnormal glucose metabolism, a year metformin treatment was effective in improving cognitive function, especially in terms of performance function(Lin et al., 2018). Metformin also produced cognitive and glucose metabolism improvement among depressed patients with diabetes mellitus(Guo et al., 2014). In patients with amnestic mild cognitive impairment or non-diabetes subjects with mild cognitive impairment or mild dementia due to $\mathrm{AD}$, metformin treatment was associated with promising cognitive enhancement(Luchsinger et al., 2016; Koenig et al., 2017). However, a population-based Mayo clinic study of aging observed that metformin was associated with an increased risk of mild cognitive impairment and was not associated with cognitive test performance(Wennberg et al., 2018). In schizophrenia, evidence suggested that metformin treatment resulted in significant reduction in weight gain and insulin resistance in patients treated with antipsychotics(Wu et al., 2008a; Wu et al., 2008b; de Silva et al., 2016). A clinical trial recruited 120 participants to investigate the impact and the related mechanism of metformin treatment on cognitive deficits of schizophrenia co-morbid metabolic syndrome (clinicaltrials.gov: NCT03271866). More longitudinal studies are needed to verify the cognitive outcomes of metformin and more works are expected to investigate whether metformin treatment is effective in enhancing cognitive performance in schizophrenia patients.

\section{GLP-1 Receptor Agonists}

GLP-1, an incretin hormone from the enteroendocrine L-cells, increases insulin secretion and reduces glucose excursion and glucagon secretion to regulate glucose metabolism. Endogenous GLP-1 is rapidly degraded by dipeptidyl peptidase-4 (DPP-4) enzyme. Therefore, the DPP-4 inhibitor (vildagliptin or sitagliptin) and the DPP-4 resistant GLP-1 analogues (exenatide, liraglutide, dulaglutide and lixisenatide) are developed to overcome the short hart-life of endogenous GLP1(Sharma et al., 2018). The activation of GLP-1 receptors in periphery and central nervous system both mediate GLP-1's food intake inhibitory and glycemic effects(Hayes, 2012). Additionally, the activation of GLP-1 receptors in the brain related to cognition exhibits neuroprotection effects, involving neuronal excitability, survival and proliferation(Mansur et al., 2018). The DPP-4 inhibitors, vildagliptin or sitagliptin, also exhibited cognitive enhancement effects(Pipatpiboon et al., 2013; Gault et al., 2015).

\section{Preclinical Studies}

In preclinical studies, GLP-1 receptor agonists protected PC12 cells from apoptosis involving EGFR transactivation and subsequent activation of the PI3K/Akt/mTOR signaling pathway(Kimura et al., 2013), and glucose metabolic aberration involving Sirt1-dependent deacetylation and Aktdependent phosphorylation of Forkhead box O (FoxO) 1(Chen et al., 2019a). Liraglutide could reverse deleterious effects of insulin resistance in neuronal cells by improving the phosphorylation status of insulin receptor, IRS-1 and Akt(Jantrapirom et al., 2020). Exendine-4, a long-acting GLP-1 receptor agonist, inhibited glucose-induced apoptosis and oxidative stress in neurons(Chen et al., 2012), and ameliorated cognitive impairment(Chen et al., 2012) involving its metabolic, anti-inflammatory and anti-oxidant effects(Solmaz et al., 2015; Abdelwahed et al., 2018). The activation of GLP-1 receptor could attenuate neuroinflammation and improve neurogenesis and insulin sensitivity in $\mathrm{AD}$ (Bae and Song, 2017). For example, dulaglutide, a novel GLP-1 receptor agonist, ameliorated STZ induced AD-like impairment of learning and memory ability by modulating hyperphosphorylation of tau and neurofilaments through improving the PI3K/AKT/GSK3 $\beta$ signaling pathway(Zhou et al., 2019). Liraglutide reversed cognitive impairment in mice and attenuated insulin receptor and synaptic pathology in a non-human primate model of $\mathrm{AD}$ (Batista et al., 2018). Specifically, in mice, 7 days liraglutide treatment prevented the loss of brain insulin receptors and synapses, and reversed memory impairment caused by intracerebroventricular administration of $A \beta$ oligomers, while systemic treatment on non-human primates with liraglutide indicated partial neuroprotection, decreasing $\mathrm{AD}$-related insulin receptor, synaptic, and tau pathology in specific brain regions(Batista et al., 2018). Moreover, in AD mouse models, administration of liraglutide could reduce $\mathrm{A} \beta$ plaques, decrease tau hyperphosphorylation and neurofilament proteins, ameliorate chronic inflammation, attenuate oxidative/ nitrosative stress, and improve cognitive function (McClean et al., 2011; Xiong et al., 2013; Hansen et al., 2015; McClean et al., 2015; Duarte et al., 2020). The combination of exenatide and insulin was associated with better memory and normal expression of insulin receptor pathway genes in a mouse model of $\mathrm{AD}$ (Robinson et al., 2019). And exenatide could improve cognitive decline through inhibiting apoptosis and promoting the BDNF-TrkB neurotrophic axis in adult wild-type mice(Bomba et al., 2018). Exenatide was reported to improve cognitive impairment by reducing $A \beta_{1-42}$ deposition, alleviating synaptic degradation, and improving hippocampal mitochondrial morphology and dynamics in the mouse model of $\mathrm{AD}(\mathrm{An}$ et al., 2019). However, another study suggested that exenatide could enhance BDNF signaling and reduce inflammation in $\mathrm{AD}$ mouse model, but it failed to promote changes in cognitive function(Bomba et al., 2019). DPP-4 inhibitors, sitagliptin and saxagliptin, also protected learning and memory function in $\mathrm{AD}$ mouse model through increasing the O-Glycosylation and decreasing abnormal phosphorylation of tau and neurofilaments (NFs), reducing intercellular $\mathrm{A} \beta$ accumulation and alleviating neurodegeneration related to GLP-1 signaling pathway(Chen et al., 2019b). Additionally, saxagliptin and vildagliptin reduced 
TABLE 2 | Clinical studies: targeting insulin pathway to improve cognitive deficits

\begin{tabular}{ll}
\hline Refs & Diagnosis \\
\hline $\begin{array}{l}\text { Benedict et al. } \\
(2004)\end{array}$ & Healthy subjects \\
\hline
\end{tabular}

(2004)

Craft et al. (2012) Adults with amnestic mild cognitive impairment or AD

$\begin{array}{ll}\text { Claxton et al. } & \text { Adults with amnestic mild } \\ (2015) & \text { cognitive impairment or AD }\end{array}$

Craft et al. (2020) Adults with amnestic mild cognitive impairment or $A D$

Cha et al. (2017) Major depressive disorder

$\begin{array}{ll}\text { Mclntyre et al. } & \text { Euthymic adults with bipolar } \\ \text { (2012) } & \text { disorder }\end{array}$

Fan et al. (2011) Nondiabetic patients with SZ or schizoaffective disorders

Fan et al. (2013) SZ or schizoaffective disorders

Guo et al. (2014) Depression with T2DM

Luchsinger et al. Amnestic mild cognitive (2016) impairment

Koenig et al. (2017)

Lin et al. (2018) NDVCl and early dementia due to $A D$
Design

Intervention(n);

Control(n)

Randomized, doubleblind, placebo-

controlled

intranasal insulin 40

IU (19);

placebo (19)

Randomized, doubleblind, placebocontrolled

intranasal insulin 20

IU (36);

intranasal insulin 40
IU (38);

placebo (30)

Randomized, doubleblind, placebocontrolled

Randomized, doubleblind, placebocontrolled

Randomized, doubleblind, placebocontrolled crossover design

Randomized, doubleblind, placebocontrolled

Single dose, doubleblind, placebocontrolled

Randomized, doubleblind, placebocontrolled

Randomized, doubleblind, placebocontrolled

Randomized, doubleblind, placebocontrolled Randomized, doubleblind, placebocontrolled, crossover study

Randomized, doubleblind intranasal insulin 20

IU (21);

intranasal insulin 40

IU (19);

placebo (20)

intranasal insulin 40

IU (119);

placebo (121);

intranasal insulin 40

IU (19);

placebo (16)

intranasal insulin 40

IU (34);

placebo (28)

single-dose of

intranasal insulin 40

IU (15);

placebo (15)

intranasal insulin 40

IU 4 times/d (21); placebo (24)

metformin (29); placebo (29)

metformin (40);

placebo (40) placebo followed by metformin (10);

metformin followed by placebo (10)

metformin + donepezil (48); acarbose + donepezil (46)
Drug, duration

Intranasal insulin $40 \mathrm{IU}$;

8-week treatment

Intranasal insulin $20 \mathrm{IU}$ or $40 \mathrm{IU}$; 4-month treatment

Intranasal insulin $20 \mathrm{IU}$ or $40 \mathrm{IU}$; 3-week treatment

Intranasal insulin $40 \mathrm{IU}$; 12 month treatment; Followed by a 6-month open label extension

intranasal insulin $40 \mathrm{IU}$;

4 times/d;

12-week treatment

Intranasal insulin $40 \mathrm{IU}$ qid;

8-week treatment

single dose of intranasal insulin $40 \mathrm{IU}$

Adjunctive intranasal insulin 40 IU 4 times/d; 8-week treatment

Metformin 1000 mg once-daily for 1 week, then daily dose increased to $1500 \mathrm{mg}$ over a period of 2 weeks (tid); 24-week treatment

Metformin, (or placebo)

1000 mg (bid);

12-month treatment

Metformin 500 mg (or placebo)

by mouth daily for 1 week, then daily dose increased to

2000 mg (bid);

16-week treatment (8 weeks metformin followed by placebo for 8 weeks or vice versa) Metformin, 500 mg (tid); Donepezil 10 mg (qn); Acarbose, 50 mg (tid); 1-year treatment
Results

Intranasal intake of insulin enhanced both consolidation of words and general mood in humans without causing systemic side effects.

Treatment with $20 \mathrm{IU}$ of insulin improved delayed memory. Both doses of insulin (20 and $40 \mathrm{IU}$ ) preserved caregiver-rated functional ability and genera cognition (the ADAS-cog score and the ADCS-ADL scale).

Daily treatment with $40 \mathrm{IU}$ insulin modulated cognition for adults with AD or mild cognitive impairment, with the apolipoprotein E-related differences in treatment response for the primary memory composite. No cognitive or functional benefits were observed with intranasal insulin treatment over a 12-month period among the primary intention-to-treat cohort. No between group differences were observed in change from baseline on total MADRS, PANAS, or on a global index of neurocognition.

Adjunctive intranasal insulin administration significantly improved a single measure of executive function in bipolar disorder.

Single-dose intranasal insulin treatment did not have a largeenough effect on verbal memory or sustained attention to be detected in this study.

There were no significant differences between the two groups at week 8 on psychopathology and cognition (PANSS and SANS).

Metformin changed glucose metabolism (HbA1c levels), improved depressive performance (MADRS and HRSD-17 scores) and cognitive function (Wechsler Memory Scale-Revised).

Metformin improved cognitive deficits (total recall of the Selective Reminding Test).

Metformin improved executive function (Trails-B) and increased orbitofrontal metabolism (Arterial Spin Label MRI).

Metformin improved cognitive function (ADAS-Cog scores; WHOUCLA AVLT TMT scores; TMT times).

(Continued on following page) 
TABLE 2 | (Continued) Clinical studies: targeting insulin pathway to improve cognitive deficits

\begin{tabular}{lll}
\hline Refs Diagnosis & Design & $\begin{array}{l}\text { Intervention(n); } \\
\text { Control(n) }\end{array}$
\end{tabular}

Mansur et al. Mood disorder (MDD or BD) Open-label

19

Liraglutide, $1.8 \mathrm{mg}, \mathrm{c}$
4-week treatment

Ishoy et al. SZ

(2017)

Watson et al.

(2019)

Watson et al.

(2005)

Hanyu et al.

(2009)

Sato et al. (2011) AD with T2DM

Yi et al. (2012) SZ

Broman-Fulks Healthy subjects

et al. (2012)

Shiina et al. $\quad S Z$

(2015)
Subjective cognitive complaints (half of subjects had family history of $A D ; 45$ 70 years old)

Mild AD or amnestic mild

cognitive deficits

AD or amnestic mild cognitive deficits
Randomized, double- exenatide (20); blind, placebo- placebo (20) controlled

Randomized, double- $\quad$ liraglutide (15); blind, placebo-

controlled

Randomized, doubleblind, placebocontrolled Randomized, open- $\quad$ pioglitazone (15); controlled

Randomized, open- $\quad$ pioglitazone (21); controlled

control (21)

rosiglitazone (9); placebo (10) blind, placebocontrolled

Randomized, doubleblind, placebocontrolled

Open-label, preliminary clinical trial

\section{Quercetin 500 mg/ Quercetin 500 mg/day;} day (309); Quercetin 1000 mg/ day (319); Placebo (313); Sulforaphane (7)

Quercetin 1000 mg/day;

12-week treatment
Exenatide, 2 mg once weekly; 3-month treatment

Liraglutide $0.6 \mathrm{mg}$ for 1 week, $1.2 \mathrm{mg}$ for 1 week, $1.8 \mathrm{mg}$ for 10 weeks, daily;

12-week treatment

Rosiglitazone, $4 \mathrm{mg}$, daily;

6-month treatment

Pioglitazone, 15 to $30 \mathrm{mg}$, daily; 6-month treatment

Pioglitazone, $15-30 \mathrm{mg}$, daily (15 mg $n=19$; 30 mg $n=2$ ); 6-month treatment

Rosiglitazone, 4 mg, daily; 8-week treatment

Sulforaphane (30 mg/day p.o);

8-week treatment
Liraglutide improved cognitive function from baseline to endpoint (the TMTB standard score and a composite Z-score comprising multiple cognitive tests (the DSST, RAVLT, Stroop test))

Non-significant result in improving cognition or psychosocial function in obese, antipsychotic-treated SZ patients (BACS, REY, SF-36, PSP, PANSS)

No detectable cognitive differences between study groups after this duration of treatment.

Rosiglitazone exhibited better delayed recall and selective attention compared to placebo.

Pioglitazone decreased FIRI and HOMA-R, and improved cognition (ADAS-Jcog scores and WMS-R logical memory-I scores).

Pioglitazone decreased plasma insulin levels, improved cognition (MMSE, ADAS-J-cog, and WMS-R logical memory-l) and regional cerebral blood flow in the parietal lobe.

No significant results in change scores of cognitive performances between two groups in clozapinetreated patients with SZ (WAIS-III, HVLT, TMT, WCST)

No significant effects of quercetin on memory, psychomotor speed, reaction time, attention or cognitive flexibility between groups.

Sulforaphane had the potential to improve some domains of cognitive function in SZ (OCLT).

NDVCl: non-dementia vascular cognitive impairment; ADAS-Cog: the Alzheimer's Disease Assessment Scale-Cognitive Subscale; WHO-UCLA AVLT: The World Health Organization-University of California-Los Angeles Auditory Verbal Learning Test; TMT: the Trail Making Test; SZ: schizophrenia; MDD: major depressive disorder; BD: bipolar disorder; TMTB: the Trail Making Test-B; DSST: Digit Symbol Substitution Test; RAVLT: Rey Auditory Verbal Learning Test; BACS: Brief Assessment of Cognition in Schizophrenia; REY: ReyOsterreith complex figure test; SF-36: the Short-Form 36 survey of the International Quality of Life Assessment; PSP: the Personal and Social Performance Scale; PANSS: Positive and Negative Syndrome Scale; SANS: the Scale for Assessment of Negative Symptoms; WAIS-III: the Digit Span subtest from the Wechsler Adult Intelligence Scale III; HVLT: the verbal fluency test, the Hopkins Verbal Learning Test; TMT: the Trail-Making Test; WCST: the Wisconsin Card Sorting Test; MMSE: the Mini-Mental State Examination; ADAS-J-cog: Alzheimer's Disease Assessment Scale-Cognitive Subscale Japanese version; ADCS-ADL: The Alzheimer's Disease Cooperative Study-activities of daily living; WMS-R logical memory-l: Wechsler Memory Scale-revised logical memory-l; FIRI: fasting immunoreactive insulin; HOMA-R: the homeostasis model assessment ratio; OCLT: the Accuracy component of the One Card Learning Task.

inflammation in streptozotocin-induced $\mathrm{AD}$ mice(Kosaraju et al., 2013a; Kosaraju et al., 2013b). Linagliptin mitigated cognitive deficits, improved brain incretin levels and attenuated $A \beta$, tau phosphorylation as well as neuroinflammation in mouse model of $\mathrm{AD}$ (Kosaraju et al., 2017). In Sprague-Dawley rats undergoing antipsychotics treatment, liraglutide ameliorated glucose metabolism dysregulation and improved cognitive deficits(Babic et al., 2018). In specific, from the start of antipsychotics treatment, liraglutide co-treatment prevented olanzapine-induced working and recognition memory deficit and obesity side-effect, and clozapine-induced reductions in recognition memory and hyperglycemia(Babic et al., 2018).

\section{Clinical Studies}

A systematic review demonstrated that GLP-1 receptor agonists induced a weight loss and improved fasting glucose and $\mathrm{HbAlc}$ in schizophrenia patients on treatment who were overweight or obese(Siskind et al., 2019). Treatment with liraglutide once-daily subcutaneous injection for 16 weeks improved glucose tolerance 
and weight gain in clozapine- and olanzapine-treated schizophrenia patients who were overweight and prediabetes compared with controls(Larsen et al., 2017). And liraglutide exhibited pro-cognitive effects in individuals with mood disorder in a 4-week, open-label study(Mansur et al., 2017).While 3 months treatment with exenatide $2 \mathrm{mg}$ once weekly failed to improve cognition in obese antipsychoticstreated schizophrenia patients(Ishoy et al., 2017). However, the study excluded patients with diabetes and the dosage, duration and statistical power may contribute to the negative results(Ishoy et al., 2017). In mid-life individuals at risk of $\mathrm{AD}$, there was an inverse correlation between insulin resistance and connectivity between bilateral hippocampal and anterior medial frontal structures(Watson et al., 2019). However, the enhancement in connectivity after liraglutide treatment was not accompanied with improved cognitive function(Watson et al., 2019). It is necessary to consider disease differences, sample size and duration of treatment when explore the effects of GLP-1 receptor agonists in cognitive function.

\section{Peroxisome Proliferator-Activated Receptors (PPAR) $\gamma$ Agonists}

PPAR $\gamma$ is a member of the nuclear receptor family that regulates gene expression by binding to DNA sequence elements termed PPAR response elements, involving in adipocyte biology, insulin action, cardiovascular disease, inflammation, renal function, and tumor biology(Lehrke and Lazar, 2005). Specific PPAR $\gamma$ ligands are divided into two major groups: endogenous or natural agonists and synthetic agonists. Evidence suggested that Thiazolidinediones, synthetic high PPAR $\gamma$-selective ligands, may constitute a potentially novel and innovative treatment approach for cognitive deficits by means of salutary effects on altered inflammatory and metabolic networks(McIntyre et al., 2007). PPAR $\gamma$ agonists may be a possible therapeutic target in neuropathological conditions, showing anti-inflammatory and anti-oxidation effects, protective action on cerebral glucose and glutamate metabolism and inducing neuronal growth factor and BDNF production(Garcia-Bueno et al., 2010).

\section{Preclinical Studies}

In neuronal seipin knock-out mice, rosiglitazone rescued the hippocampal LTP induction and ameliorated spatial cognitive deficits(Zhou et al., 2016). Pioglitazone also exhibited learning and memory improvement in alcohol-induced neuronal damage rats(Cippitelli et al., 2017). Monotherapy or combination of pioglitazone and exenatide improved cognitive function, decreased hippocampal neurodegeneration and reduced microglia overexpression in insulin resistant $\operatorname{rats}(\mathrm{Gad}$ et al., 2016). In a mouse model of $\mathrm{AD}$, pioglitazone and fenofibrate combined treatment ameliorated memory and cognitive impairment via modulation of the Wnt/beta catenin pathway, accompanied with a reduction in neuronal damage(Assaf et al., 2020). Pioglitazone could rescue impaired synaptic deficits and spatial memory in $\mathrm{AD}$ transgenic mice through inhibiting cyclindependent kinase 5 activity and reversing $A \beta$-induced dendritic spine loss(Chen et al., 2015). The chronic treatment of AD transgenic mice with pioglitazone or rosiglitazone for 4 months improved spatial learning, enhanced AKT signaling and attenuated tau hyperphosphorylation and neuroinflammation(Yu et al., 2015). Rosiglitazone rescued AD pathology and restored the hippocampal function, leading to a rescue of memory impairment in 9-month-old AD transgenic mice(Escribano et al., 2010). Rosiglitazone showed cognitive improvement through multiple ways such as regulating extracellular signal-regulated protein kinase MAPK signaling transduction(Denner et al., 2012), and affecting neuronal ion channel and synaptic plasticity in the brain of Tg2576(Nenov et al., 2014; Hsu et al., 2017), an extensively characterized AD mouse model.

\section{Clinical Studies}

Anti-diabetic agents, PPAR $\gamma$ agonists, might have the procognitive effects in subjects with $\mathrm{AD} / \mathrm{mild}$ cognitive impairment with good acceptability(Cao et al., 2018). In patients with mild $\mathrm{AD}$ or amnestic mild cognitive deficits, 6months treatment of rosiglitazone exhibited cognitive improvement compared with placebo(Watson et al., 2005). Pioglitazone also ameliorated glucose metabolism and cognitive function in $\mathrm{AD}$ (Hanyu et al., 2009; Sato et al., 2011). However, a systematic review including nine eligible studies suggested that there was insufficient evidence to support the cognitive benefits of rosiglitazone in $\mathrm{AD}$ and amnestic mild cognitive impairment patients although the efficacy of pioglitazone was promising in patients with comorbid diabetes(Liu et al., 2015). A study demonstrated that among antipsychotics-treated patients with schizophrenia, there was a significant association of PPAR $\gamma$ gene in altered glucose levels and psychosis profile(Liu et al., 2014). Arulmozhi suggested a possible role of PPAR agonists in antipsychotic-induced insulin resistance rodents(Arulmozhi et al., 2006), and such medications were related with BDNF levels in schizophrenia, which might play a part in the management of this illness(d'Angelo et al., 2019). In a small pilot clinical trial, rosiglitazone treatment for 8 weeks failed to show the potential cognitive benefit in schizophrenia patients treated with clozapine(Yi et al., 2012). It is not clear whether PPAR $\gamma$ agonists improve cognitive function in schizophrenia and disease and medicine differences should be considered at the same time. More works with larger sample size and longer treatment duration are needed.

\section{Others}

\section{SGLT2 Inhibitors}

Sodium-glucose co-transporter (SGLT) inhibitors are one of the newly developed medications used to treat T2DM(Chao and Henry, 2010). SGLT 2 inhibitors, such as dapagliflozin and empagliflozin, decrease renal glucose reabsorption, resulting in enhanced urinary glucose excretion and subsequent reductions in plasma glucose and glycosylated hemoglobin concentrations(Nauck, 2014). SGLT2 inhibitors could improve insulin sensitivity and glucose homeostasis via reducing glucotoxicity, improving $\beta$ cell function, reducing oxidative damages and inflammatory processes and inducing caloric disposition and weight loss(Yaribeygi et al., 2020). 
Dapagliflozin could improve brain insulin sensitivity, alleviate brain mitochondrial dysfunction, attenuate brain apoptosis and brain inflammation, and preserve hippocampal synaptic plasticity(Sa-nguanmoo et al., 2017). However, no sufficient preclinical and powered clinical studies have elucidated the cognitive benefit of SGLT2 inhibitors in AD and schizophrenia.

\section{Quercetin}

As a natural pigment, quercetin is a flavonoid with abundant biological activities such as antiviral, anticancer, antioxidation, anti-inflammatory, and antidiabetic activity(Batiha et al., 2020). The antidiabetic effects of quercetin involve the inhibition of intestinal glucose absorption, insulin secretory and insulinsensitizing activities as well as the enhancement of glucose utilization in peripheral tissues(Eid and Haddad, 2017). A meta-analysis supported that the flavonoid quercetin lowered the serum glucose level at dose of 10,25 and $50 \mathrm{mg} / \mathrm{kg}$ in diabetic animals(Bule et al., 2019). Additionally, quercetin could suppress endoplasmic reticulum stress and tau phosphorylation through its AMPK activity to provide potential cognitive benefit(Chen et al., 2016). Quercetin exhibited neuroprotection through its effects on sodium channels of neurons(Yao et al., 2010), and modulating Akt signaling pathway to inhibit neuronal apoptosis(Pei et al., 2016). Quercetin ameliorated cognitive and emotional impairment, reversed brain levels of $\beta$-amyloidosis and tauopathy, attenuated mitochondrial dysfunction and alleviated astrogliosis and microgliosis in $\mathrm{AD}$ mice model(Wang et al., 2014; Sabogal-Guáqueta et al., 2015). Quercetin exhibited spatial learning and memory improvement in Parkinson's Disease model via its antioxidant effect resulting in the promotion of neuron survival(Sriraksa et al., 2012). Quercetin also improved the chronic unpredicted stress-mediated memory dysfunction through normalizing metabolic aberration, attenuating insulin resistance, elevating hippocampal GLUT4 levels, and maintaining neuronal integrity(Mehta et al., 2017). In a ketamine model of schizophrenia, quercetin showed the potential to improve cognitive deficits, partly owing to its ability to scavenge free radicals and its high antioxidant capacity(Mert et al., 2019). However, a clinical study failed to demonstrate the effects of a 12-week quercetin supplementation program on cognitive function(Broman-Fulks et al., 2012). There may exist some gaps when translate in vitro studies and in vivo experiments into clinical situation and more clinical studies are needed to determine whether quercetin shows cognitive benefits.

\section{Sulforaphane}

Sulforaphane is a compound with multiple bioactivities such as antidiabetic and antioxidant effects. Sulforaphane could improve glucose tolerance through up-regulation of insulin signaling involving IRS-1/Akt/GLUT 4 pathway in muscle(Xu et al., 2018). Sulforaphane also attenuated glucose intolerance and affected GLUT3 expression in the cerebral cortex and hypothalamus(Souza et al., 2013). Sulforaphane mitigated cognitive decline which was associated with an upregulation of the nuclear accumulation and transcriptional function of the nuclear factor erythroid 2-related factors (Nrf2) and an enhancement of the antioxidative response in the
hippocampus(Pu et al., 2018). The transcription factor Nrf2 functions at the interface of cellular redox and intermediary metabolism(Dinkova-Kostova et al., 2018), which modulates the expression of defensive genes encoding detoxifying enzymes and antioxidant proteins(Kaspar et al., 2009). In addition to regulating the expression of antioxidant genes, Nrf2 has also been shown to exhibit anti-inflammation effects and modulate mitochondrial function and biogenesis(Brandes and Gray, 2020). Sulforaphane prevented olanzapine-induced glucose and lipid metabolism dysregulation in preclinical studies(Isaacson et al., 2020). In phencyclidine administration mice, sulforaphane ameliorated hyperlocomotion and pre-pulse inhibition deficits(Shirai et al., 2012). Additionally, sulforaphane exhibited prophylactic and therapeutic effects in phencyclidineinduced cognitive deficits, which was substantiated by the results of Novel Object Recognition test(Shirai et al., 2015). A small open label clinical research suggested that sulforaphane had the potential to improve some domains of cognitive function in schizophrenia, although it failed to detect any statistical differences of the serum level of BDNF after taking sulforaphane for 8 weeks to baseline(Shiina et al., 2015). A 6month clinical trial was conducted to evaluate whether adding sulforaphane treatment would benefit the negative symptoms and cognitive function in individuals with schizophrenia (clinicaltrials.gov: NCT04521868). Larger randomized, doubleblind, placebo-controlled trials conducted over longer periods are needed to determine the efficacy and safety of sulforaphane.

\section{CONCLUSION}

Cognitive deficits occur in neurodegenerative and neuropsychiatric diseases including $\mathrm{AD}$ and schizophrenia. Insulin resistance is a shared metabolic comorbidity of these two chronic diseases. The disruption of insulin action in the brain is considered as a potentially important pathophysiological mechanism of cognitive impairment via deficits in neuronal structure and function, impaired synaptic plasticity, brain mitochondrial dysfunction, increased oxidative stress and inflammation. Intrinsic abnormal glucose metabolism would predispose $\mathrm{AD}$ and schizophrenia patients to cognitive deficits and current therapeutic measures cannot achieve expected therapeutic efficacy. Therapeutic interventions may be effective if both the periphery and brain glucose metabolic disruptions are alleviated for effective results. Antidiabetic agents have gained public and scientific attention for its potential as a cognitive enhancement drug and is currently being examined in in vitro experiment, in preclinical animal studies and in clinical trials around the word. The molecular mechanism and preclinical animal models suggest that the repositioning of antidiabetic drugs is a promising opportunity to alleviate cognitive deficits in $\mathrm{AD}$ and schizophrenia. However, there may exist some gaps when translate experimental results into application. Drugs specifically designed to target brain insulin resistance may exert beneficial effects on cognition. Furthermore, the pathogenesis and clinical heterogeneity of cognitive impairment remain complex. A better understanding of the 
relationship between brain insulin resistance and cognitive impairment will help us to design future research. More works are urgent to explore the nature and corelates of brain insulin resistance and cognitive deficits in schizophrenia. For example, preclinical models are expected to discover the molecular and cellular mechanisms of cognitive deficits in schizophrenia, such as cerebral organoids derived from human embryonic stem cells and patient-derived induced pluripotent stem cells from schizophrenia, which are able to clarify the pathogenesis of cognitive deficits and the role of brain insulin resistance to exclude the effects of antipsychotics on this relationship. Additionally, radiotracer or detection methods are expected to clarify the central insulin action in patients with schizophrenia. Some anti-diabetic agents may fail as cognitive enhancement strategies for a number of reasons, such as poor penetrance of the blood-brain barrier and ineffectiveness in reducing brain insulin resistance in vivo. Therefore, works are needed to examine the effect of drugs that are able to increase the sensitivity of insulin receptors in the brain. Besides, multi-site large-scale randomized controlled trails are needed to examine the effects of antidiabetic medications on cognition in schizophrenia. In the future, more works are expected to elucidate the relationship between brain insulin resistance and cognitive dysfunction in schizophrenia leading to the development of novel interventions to alleviate cognitive deficits in schizophrenia to benefit patients.

\section{REFERENCES}

Abdelwahed, O. M., Tork, O. M., Gamal El Din, M. M., Rashed, L., and Zickri, M. (2018). Effect of Glucagon-like Peptide-1 Analogue; Exendin-4, on Cognitive Functions in Type 2 Diabetes Mellitus; Possible Modulation of Brain Derived Neurotrophic Factor and Brain Visfatin. Brain Res. Bull. 139, 67-80. doi:10. 1016/j.brainresbull.2018.02.002

Agarwal, S. M., Caravaggio, F., Costa-Dookhan, K. A., Castellani, L., Kowalchuk, C., Asgariroozbehani, R., et al. (2020). Brain Insulin Action in Schizophrenia: Something Borrowed and Something New. Neuropharmacology 163, 107633. doi:10.1016/j.neuropharm.2019.05.010

Agarwal, S. M., Kowalchuk, C., Castellani, L., Costa-Dookhan, K. A., Caravaggio, F., Asgariroozbehani, R., et al. (2020). Brain Insulin Action: Implications for the Treatment of Schizophrenia. Neuropharmacology 168, 107655. doi:10.1016/j. neuropharm.2019.05.032

Almeida-Suhett, C. P., Graham, A., Chen, Y., and Deuster, P. (2017). Behavioral Changes in Male Mice Fed a High-Fat Diet Are Associated with IL-1 $\beta$ Expression in Specific Brain Regions. Physiol. Behav. 169, 130-140. doi:10. 1016/j.physbeh.2016.11.016

An, J., Zhou, Y., Zhang, M., Xie, Y., Ke, S., Liu, L., et al. (2019). Exenatide Alleviates Mitochondrial Dysfunction and Cognitive Impairment in the $5 \times$ FAD Mouse Model of Alzheimer's Disease. Behav. Brain Res. 370, 111932. doi:10.1016/j.bbr. 2019.111932

André, C., O’Connor, J. C., Kelley, K. W., Lestage, J., Dantzer, R., and Castanon, N. (2008). Spatio-temporal Differences in the Profile of Murine Brain Expression of Proinflammatory Cytokines and Indoleamine 2,3-dioxygenase in Response to Peripheral Lipopolysaccharide Administration. J. Neuroimmunology 200 (1), 90-99. doi:10.1016/j.jneuroim.2008.06.011

Arulmozhi, D. K., Dwyer, D. S., and Bodhankar, S. L. (2006). Antipsychotic Induced Metabolic Abnormalities: an Interaction Study with Various PPAR Modulators in Mice. Life Sci. 79 (19), 1865-1872. doi:10.1016/j.lfs.2006.06.016 Assaf, N., El-Shamarka, M. E., Salem, N. A., Khadrawy, Y. A., and El Sayed, N. S. (2020). Neuroprotective Effect of PPAR Alpha and Gamma Agonists in a Mouse Model of Amyloidogenesis through Modulation of the Wnt/beta

\section{AUTHOR CONTRIBUTIONS}

QC was responsible for manuscript preparation and literature search. TC and NL aided in manuscript preparation, literature search, and manuscript revision. CZ, SZ and XW assisted in literature review and provided revisions. $\mathrm{BZ}$ and $\mathrm{HC}$ conceived of the review and provided feedback and revisions to the manuscript. All authors contributed to and have approved the final manuscript.

\section{FUNDING}

This work was supported in part by the grants from Hunan Provincial Health Commission Research Project (202113010595), Wu Jieping Medical Foundation Funded Special Clinical Research Project (320.6750.2020-04-2), Changsha Municipal Natural Science Foundation (kq2007045) and the Fundamental Research Funds for the Central Universities of Central South University (2019zzts1049, 2020zzts884).

\section{ACKNOWLEDGMENTS}

We thank Prof. Huande Li, who kindly assisted with the preparation and proof-reading of the manuscript.

Catenin Pathway via Targeting Alpha- and Beta-Secretases. Prog. NeuroPsychopharmacology Biol. Psychiatry 97, 109793. doi:10.1016/j.pnpbp.2019. 109793

Avgerinos, K. I., Kalaitzidis, G., Malli, A., Kalaitzoglou, D., Myserlis, P. G., and Lioutas, V.-A. (2018). Intranasal Insulin in Alzheimer's Dementia or Mild Cognitive Impairment: a Systematic Review. J. Neurol. 265 (7), 1497-1510. doi:10.1007/s00415-018-8768-0

Babic, I., Gorak, A., Engel, M., Sellers, D., Else, P., Osborne, A. L., et al. (2018). Liraglutide Prevents Metabolic Side-Effects and Improves Recognition and Working Memory during Antipsychotic Treatment in Rats. J. Psychopharmacol. 32 (5), 578-590. doi:10.1177/0269881118756061

Bae, C., and Song, J. (2017). The Role of Glucagon-Like Peptide 1 (GLP1) in Type 3 Diabetes: GLP-1 Controls Insulin Resistance, Neuroinflammation and Neurogenesis in the Brain. Int. J. Mol. Sci. 18 (11), 2493. doi:10.3390/ ijms 18112493

Barhwal, K., Das, S. K., Kumar, A., Hota, S. K., and Srivastava, R. B. (2015). Insulin Receptor A and Sirtuin 1 Synergistically Improve Learning and Spatial Memory Following Chronic Salidroside Treatment during Hypoxia. J. Neurochem. 135 (2), 332-346. doi:10.1111/jnc.13225

Batiha, G. E.-S., Beshbishy, A. M., Ikram, M., Mulla, Z. S., El-Hack, M. E. A., Taha, A. E., et al. (2020). The Pharmacological Activity, Biochemical Properties, and Pharmacokinetics of the Major Natural Polyphenolic Flavonoid: Quercetin. Foods 9 (3), 374. doi:10.3390/foods9030374

Batista, A. F., Forny-Germano, L., Clarke, J. R., Lyra e Silva, N. M., Brito-Moreira, J., Boehnke, S. E., et al. (2018). The Diabetes Drug Liraglutide Reverses Cognitive Impairment in Mice and Attenuates Insulin Receptor and Synaptic Pathology in a Non-human Primate Model of Alzheimer's Disease. J. Pathol. 245 (1), 85-100. doi:10.1002/path.5056

Benedict, C., Brooks, S. J., Kullberg, J., Burgos, J., Kempton, M. J., Nordenskjöld, R., et al. (2012). Impaired Insulin Sensitivity as Indexed by the HOMA Score Is Associated With Deficits in Verbal Fluency and Temporal Lobe Gray Matter Volume in the Elderly. Diabetes Care 35 (3), 488-494. doi:10.2337/ dc11-2075

Benedict, C., Hallschmid, M., Hatke, A., Schultes, B., Fehm, H. L., Born, J., et al. (2004). Intranasal Insulin Improves Memory in Humans. 
Psychoneuroendocrinology 29 (10), 1326-1334. doi:10.1016/j.psyneuen.2004. 04.003

Biessels, G. J., and Reagan, L. P. (2015). Hippocampal Insulin Resistance and Cognitive Dysfunction. Nat. Rev. Neurosci. 16 (11), 660-671. doi:10.1038/ nrn4019

Boitard, C., Cavaroc, A., Sauvant, J., Aubert, A., Castanon, N., Layé, S., et al. (2014). Impairment of Hippocampal-dependent Memory Induced by juvenile HighFat Diet Intake Is Associated with Enhanced Hippocampal Inflammation in Rats. Brain Behav. Immun. 40, 9-17. doi:10.1016/j.bbi.2014.03.005

Bomba, M., Granzotto, A., Castelli, V., Massetti, N., Silvestri, E., Canzoniero, L. M. T., et al. (2018). Exenatide Exerts Cognitive Effects by Modulating the BDNFTrkB Neurotrophic Axis in Adult Mice. Neurobiol. Aging 64, 33-43. doi:10. 1016/j.neurobiolaging.2017.12.009

Bomba, M., Granzotto, A., Castelli, V., Onofrj, M., Lattanzio, R., Cimini, A., et al. (2019). Exenatide Reverts the High-Fat-Diet-Induced Impairment of BDNF Signaling and Inflammatory Response in an Animal Model of Alzheimer's Disease. J. Alzheimers Dis. 70 (3), 793-810. doi:10.3233/jad-190237

Bora, E., Akdede, B. B., and Alptekin, K. (2016). The Relationship between Cognitive Impairment in Schizophrenia and Metabolic Syndrome: a Systematic Review and Meta-Analysis. Psychol. Med. 47 (6), 1030-1040. doi:10.1017/s0033291716003366

Brandes, M. S., and Gray, N. E. (2020). NRF2 as a Therapeutic Target in Neurodegenerative Diseases. ASN Neuro 12, 175909141989978. doi:10.1177/ 1759091419899782

Brigadski, T., and Leßmann, V. (2020). The Physiology of Regulated BDNF Release. Cell Tissue Res 382 (1), 15-45. doi:10.1007/s00441-020-03253-2

Broman-Fulks, J. J., Canu, W. H., Trout, K. L., and Nieman, D. C. (2012). The Effects of Quercetin Supplementation on Cognitive Functioning in a Community Sample: a Randomized, Placebo-Controlled Trial. Ther. Adv. 2 (4), 131-138. doi:10.1177/2045125312445894

Bule, M., Abdurahman, A., Nikfar, S., Abdollahi, M., and Amini, M. (2019). Antidiabetic Effect of Quercetin: A Systematic Review and Meta-Analysis of Animal Studies. Food Chem. Toxicol. 125, 494-502. doi:10.1016/j.fct.2019. 01.037

Cao, B., Rosenblat, J. D., Brietzke, E., Park, C., Lee, Y., Musial, N., et al. (2018). Comparative Efficacy and Acceptability of Antidiabetic Agents for Alzheimer's Disease and Mild Cognitive Impairment: A Systematic Review and Network Meta-Analysis. Diabetes Obes. Metab. 20 (10), 2467-2471. doi:10.1111/dom. 13373

Cha, D. S., Best, M. W., Bowie, C. R., Gallaugher, L. A., Woldeyohannes, H. O., Soczynska, J. K., et al. (2017). A Randomized, Double-Blind, PlaceboControlled, Crossover Trial Evaluating the Effect of Intranasal Insulin on Cognition and Mood in Individuals with Treatment-Resistant Major Depressive Disorder. J. Affective Disord. 210, 57-65. doi:10.1016/j.jad.2016. 12.006

Chao, E. C., and Henry, R. R. (2010). SGLT2 Inhibition - a Novel Strategy for Diabetes Treatment. Nat. Rev. Drug Discov. 9 (7), 551-559. doi:10.1038/ $\operatorname{nrd} 3180$

Chen, J., Deng, X., Liu, N., Li, M., Liu, B., Fu, Q., et al. (2016). Quercetin Attenuates Tau Hyperphosphorylation and Improves Cognitive Disorder via Suppression of ER Stress in a Manner Dependent on AMPK Pathway. J. Funct. Foods 22, 463-476. doi:10.1016/j.jff.2016.01.036

Chen, J., Li, S., Sun, W., and Li, J. (2015). Anti-diabetes Drug Pioglitazone Ameliorates Synaptic Defects in AD Transgenic Mice by Inhibiting Cyclindependent Kinase5 Activity. PLoS One 10 (4), e0123864. doi:10.1371/journal. pone. 0123864

Chen, S., Liu, A.-r., An, F.-m., Yao, W.-b., and Gao, X.-d. (2012). Amelioration of Neurodegenerative Changes in Cellular and Rat Models of Diabetes-Related Alzheimer's Disease by Exendin-4. Age 34 (5), 1211-1224. doi:10.1007/s11357011-9303-8

Chen, S., Tang, Q., Wang, Y., Xu, Z., Chen, S.-T., Sun, Y., et al. (2019a). Evidence of Metabolic Memory-Induced Neurodegeneration and the Therapeutic Effects of Glucagon-like Peptide-1 Receptor Agonists via Forkhead Box Class O. Biochim. Biophys. Acta (BBA) - Mol. Basis Dis. 1865 (2), 371-377. doi:10.1016/j.bbadis. 2018.11.012

Chen, S., Zhou, M., Sun, J., Guo, A., Fernando, R. L., Chen, Y., et al. (2019b). DPP-4 Inhibitor Improves Learning and Memory Deficits and AD-like
Neurodegeneration by Modulating the GLP-1 Signaling. Neuropharmacology 157, 107668. doi:10.1016/j.neuropharm.2019.107668

Chen, Y., Zhao, S., Fan, Z., Li, Z., Zhu, Y., Shen, T., et al. (2021). Metformin Attenuates Plaque-Associated Tau Pathology and Reduces Amyloid- $\beta$ burden in APP/PS1 Mice. Alz Res. Ther. 13 (1), 40. doi:10.1186/s13195-020-00761-9

Chen, Y., Zhao, Y., Dai, C.-1., Liang, Z., Run, X., Iqbal, K., et al. (2014). Intranasal Insulin Restores Insulin Signaling, Increases Synaptic Proteins, and Reduces A $\beta$ Level and Microglia Activation in the Brains of 3xTg-AD Mice. Exp. Neurol. 261, 610-619. doi:10.1016/j.expneurol.2014.06.004

Cippitelli, A., Domi, E., Ubaldi, M., Douglas, J. C., Li, H. W., Demopulos, G., et al. (2017). Protection against Alcohol-Induced Neuronal and Cognitive Damage by the PPAR $\gamma$ Receptor Agonist Pioglitazone. Brain Behav. Immun. 64, 320-329. doi:10.1016/j.bbi.2017.02.001

Citri, A., and Malenka, R. C. (2008). Synaptic Plasticity: Multiple Forms, Functions, and Mechanisms. Neuropsychopharmacol 33 (1), 18-41. doi:10.1038/sj.npp. 1301559

Claxton, A., Baker, L. D., Hanson, A., Trittschuh, E. H., Cholerton, B., Morgan, A., et al. (2015). Long-Acting Intranasal Insulin Detemir Improves Cognition for Adults with Mild Cognitive Impairment or Early-Stage Alzheimer's Disease Dementia. J. Alzheimers Dis. 44, 897-906. doi:10.3233/JAD-141791

Claxton, A., Baker, L. D., Wilkinson, C. W., Trittschuh, E. H., Chapman, D., Watson, G. S., et al. (2013). Sex and ApoE Genotype Differences in Treatment Response to Two Doses of Intranasal Insulin in Adults with Mild Cognitive Impairment or Alzheimer's Disease. J. Alzheimers Dis. 35, 789-797. doi:10. 3233/JAD-122308

Clay, H. B., Sillivan, S., and Konradi, C. (2011). Mitochondrial Dysfunction and Pathology in Bipolar Disorder and Schizophrenia. Int. J. Dev. Neurosci. 29 (3), 311-324. doi:10.1016/j.ijdevneu.2010.08.007

Craft, S., Baker, L. D., Montine, T. J., Minoshima, S., Watson, G. S., Claxton, A., et al. (2012). Intranasal Insulin Therapy for Alzheimer Disease and Amnestic Mild Cognitive Impairment. Arch. Neurol. 69 (1), 29-38. doi:10.1001/ archneurol.2011.233

Craft, S., Raman, R., Chow, T. W., Rafii, M. S., Sun, C.-K., Rissman, R. A., et al. (2020). Safety, Efficacy, and Feasibility of Intranasal Insulin for the Treatment of Mild Cognitive Impairment and Alzheimer Disease Dementia. JAMA Neurol. 77 (9), 1099-1109. doi:10.1001/jamaneurol.2020.1840

Creese, B., Vassos, E., Vassos, E., Bergh, S., Athanasiu, L., Johar, I., et al. (2019). Examining the Association between Genetic Liability for Schizophrenia and Psychotic Symptoms in Alzheimer's Disease. Transl Psychiatry 9 (1), 273. doi:10.1038/s41398-019-0592-5

d'Angelo, M., Castelli, V., Catanesi, M., Antonosante, A., Dominguez-Benot, R., Ippoliti, R., et al. (2019). PPAR $\gamma$ and Cognitive Performance. Int. J. Mol. Sci. 20 (20). doi:10.3390/ijms20205068

de Silva, V. A., Suraweera, C., Ratnatunga, S. S., Dayabandara, M., Wanniarachchi, N., and Hanwella, R. (2016). Metformin in Prevention and Treatment of Antipsychotic Induced Weight Gain: a Systematic Review and MetaAnalysis. BMC Psychiatry 16 (1), 341. doi:10.1186/s12888-016-1049-5

Denner, L. A., Rodriguez-Rivera, J., Haidacher, S. J., Jahrling, J. B., Carmical, J. R., Hernandez, C. M., et al. (2012). Cognitive Enhancement with Rosiglitazone Links the Hippocampal PPAR and ERK MAPK Signaling Pathways. J. Neurosci. 32 (47), 16725-16735. doi:10.1523/jneurosci.2153-12.2012

Ding, S., Zhuge, W., Yang, J., Wen, F., Xu, Z., Wang, X., et al. (2017). Insulin Resistance Disrupts the Interaction Between AKT and the NMDA Receptor and the Inactivation of the CaMKIV/CREB Pathway in Minimal Hepatic Encephalopathy. Toxicol. Sci. 159 (2), 290-306. doi:10.1093/toxsci/kfx093

Dinkova-Kostova, A. T., Kostov, R. V., and Kazantsev, A. G. (2018). The Role of Nrf2 Signaling in Counteracting Neurodegenerative Diseases. Febs J. 285 (19), 3576-3590. doi:10.1111/febs.14379

Drejer, K., Vaag, A., Bech, K., Hansen, P., Sørensen, A. R., and Mygind, N. (1992). Intranasal Administration of Insulin With Phospholipid as Absorption Enhancer: Pharmacokinetics in Normal Subjects. Diabetic Med. 9 (4), 335-340. doi:10.1111/j.1464-5491.1992.tb01792.x

Duarte, A. I., Candeias, E., Alves, I. N., Mena, D., Silva, D. F., Machado, N. J., et al. (2020). Liraglutide Protects Against Brain Amyloid- $\beta 1-42$ Accumulation in Female Mice with Early Alzheimer's Disease-Like Pathology by Partially Rescuing Oxidative/Nitrosative Stress and Inflammation. Int. J. Mol. Sci. 21 (5), 1746. doi:10.3390/ijms21051746 
Eid, H. M., and Haddad, P. S. (2017). The Antidiabetic Potential of Quercetin: Underlying Mechanisms. Curr. Med. Chem. 24 (4), 355-364. doi:10.2174/ 0929867323666160909153707

Ekblad, L. L., Rinne, J. O., Puukka, P., Laine, H., Ahtiluoto, S., Sulkava, R., et al. (2017). Insulin Resistance Predicts Cognitive Decline: An 11-Year Follow-Up of a Nationally Representative Adult Population Sample. Dia. Care 40 (6), 751-758. doi:10.2337/dc16-2001

Escribano, L., Simón, A.-M., Gimeno, E., Cuadrado-Tejedor, M., López de Maturana, R., García-Osta, A., et al. (2010). Rosiglitazone Rescues Memory Impairment in Alzheimer's Transgenic Mice: Mechanisms Involving a Reduced Amyloid and Tau Pathology. Neuropsychopharmacol 35 (7), 1593-1604. doi:10. 1038/npp.2010.32

Fan, X., Copeland, P. M., Liu, E. Y., Chiang, E., Freudenreich, O., Goff, D. C., et al. (2011). No Effect of Single-Dose Intranasal Insulin Treatment on Verbal Memory and Sustained Attention in Patients With Schizophrenia. J. Clin. Psychopharmacol. 31 (2), 231-234. doi:10.1097/JCP.0b013e31820ebd0e

Fan, X., Liu, E., Freudenreich, O., Copeland, P., Hayden, D., Ghebremichael, M., et al. (2013). No Effect of Adjunctive, Repeated-Dose Intranasal Insulin Treatment on Psychopathology and Cognition in Patients with Schizophrenia. J. Clin. Psychopharmacol. 33 (2), 226-230. doi:10.1097/JCP. 0b013e31828701d0

Fang, W., Zhang, J., Hong, L., Huang, W., Dai, X., Ye, Q., et al. (2020). Metformin Ameliorates Stress-Induced Depression-like Behaviors via Enhancing the Expression of BDNF by Activating AMPK/CREB-mediated Histone Acetylation. J. Affective Disord. 260, 302-313. doi:10.1016/j.jad.2019.09.013

Farr, S. A., Roesler, E., Niehoff, M. L., Roby, D. A., McKee, A., and Morley, J. E. (2019). Metformin Improves Learning and Memory in the SAMP8 Mouse Model of Alzheimer's Disease. J. Alzheimers Dis. 68, 1699-1710. doi:10.3233/ JAD-181240

Farzampour, S., Majdi, A., and Sadigh-Eteghad, S. (2016). Intranasal Insulin Treatment Improves Memory and Learning in a Rat Amyloid-Beta Model of Alzheimer's Disease. Physiol. Int. 103 (3), 344-353. doi:10.1556/2060.103. 2016.3.7

Fernandez, A., Meechan, D. W., Karpinski, B. A., Paronett, E. M., Bryan, C. A., Rutz, H. L., et al. (2019). Mitochondrial Dysfunction Leads to Cortical UnderConnectivity and Cognitive Impairment. Neuron 102 (6), 1127-1142. doi:10. 1016/j.neuron.2019.04.013

Fourrier, C., Singhal, G., and Baune, B. T. (2019). Neuroinflammation and Cognition across Psychiatric Conditions. CNS Spectr. 24 (1), 4-15. doi:10. 1017/S1092852918001499

Freiherr, J., Hallschmid, M., Frey, W. H., Brünner, Y. F., Chapman, C. D., Hölscher, C., et al. (2013). Intranasal Insulin as a Treatment for Alzheimer's Disease: A Review of Basic Research and Clinical Evidence. CNS Drugs 27 (7), 505-514. doi:10.1007/s40263-013-0076-8

Gad, E. S., Zaitone, S. A., and Moustafa, Y. M. (2016). Pioglitazone and Exenatide Enhance Cognition and Downregulate Hippocampal Beta Amyloid Oligomer and Microglia Expression in Insulin-Resistant Rats. Can. J. Physiol. Pharmacol. 94 (8), 819-828. doi:10.1139/cjpp-2015-0242

García-Bueno, B., Pérez-Nievas, B. G., and Leza, J. C. (2010). Is There a Role for the Nuclear Receptor PPAR $\gamma$ in Neuropsychiatric Diseases? Int. J. Neuropsychopharm. 13 (10), 1411-1429. doi:10.1017/s1461145710000970

Gault, V. A., Lennox, R., and Flatt, P. R. (2015). Sitagliptin, A Dipeptidyl Peptidase4 Inhibitor, Improves Recognition Memory, Oxidative Stress and Hippocampal Neurogenesis and Upregulates Key Genes Involved in Cognitive Decline. Diabetes Obes. Metab. 17 (4), 403-413. doi:10.1111/dom.12432

Gong, C.-Y., Li, Z., Wang, H.-M., Liu, J., Chen, L., Zhang, H.-W., et al. (2011). Targeting the Kynurenine Pathway as a Potential Strategy to Prevent and Treat Alzheimer's Disease. Med. Hypotheses 77 (3), 383-385. doi:10.1016/j.mehy. 2011.05.022

Grillo, C. A., Piroli, G. G., Lawrence, R. C., Wrighten, S. A., Green, A. J., Wilson, S. P., et al. (2015). Hippocampal Insulin Resistance Impairs Spatial Learning and Synaptic Plasticity. Diabetes 64 (11), 3927-3936. doi:10.2337/db15-0596

Guo, M., Mi, J., Jiang, Q.-M., Xu, J.-M., Tang, Y.-Y., Tian, G., et al. (2014). Metformin May Produce Antidepressant Effects through Improvement of Cognitive Function Among Depressed Patients with Diabetes Mellitus. Clin. Exp. Pharmacol. Physiol. 41 (9), 650. doi:10.1111/1440-1681.12265

Gupta, A., Bisht, B., and Dey, C. S. (2011). Peripheral Insulin-Sensitizer Drug Metformin Ameliorates Neuronal Insulin Resistance and Alzheimer's-like
Changes. Neuropharmacology 60 (6), 910-920. doi:10.1016/j.neuropharm. 2011.01.033

Haar, H. J. V. D., Burgmans, S., Jansen, J. F. A., Osch, M. J. P. V., Buchem, M. A. V., Muller, M., et al. (2016). Blood-Brain Barrier Leakage in Patients with Early Alzheimer Disease. Radiology 281 (2), 527-535. doi:10.1148/radiol.2016152244

Hackinger, S., Prins, B., Mamakou, V., Zengini, E., Marouli, E., Brčić, L., et al. (2018). Evidence for Genetic Contribution to the Increased Risk of Type 2 Diabetes in Schizophrenia. Transl Psychiatry 8 (1), 252. doi:10.1038/s41398018-0304-6

Hansen, H. H., Fabricius, K., Barkholt, P., Niehoff, M. L., Morley, J. E., Jelsing, J., et al. (2015). The GLP-1 Receptor Agonist Liraglutide Improves Memory Function and Increases Hippocampal CA1 Neuronal Numbers in a Senescence-Accelerated Mouse Model of Alzheimer's Disease. J. Alzheimers Dis. 46 (4), 877-888. doi:10.3233/jad-143090

Hanyu, H., Sato, T., Kiuchi, A., Sakurai, H., and Iwamoto, T. (2009). Pioglitazone Improved Cognition in a Pilot Study on Patients with Alzheimer's Disease and Mild Cognitive Impairment with Diabetes Mellitus. J. Am. Geriatr. Soc. 57 (1), 177-179. doi:10.1111/j.1532-5415.2009.02067.x

Hayes, M. R. (2012). Neuronal and Intracellular Signaling Pathways Mediating GLP-1 Energy Balance and Glycemic Effects. Physiol. Behav. 106 (3), 413-416. doi:10.1016/j.physbeh.2012.02.017

Hill, S. K., Bishop, J. R., Palumbo, D., and Sweeney, J. A. (2010). Effect of SecondGeneration Antipsychotics on Cognition: Current Issues and Future Challenges. Expert Rev. Neurotherapeutics 10 (1), 43-57. doi:10.1586/ern. 09.143

Hsu, W.-C. J., Wildburger, N. C., Haidacher, S. J., Nenov, M. N., Folorunso, O., Singh, A. K., et al. (2017). PPARgamma Agonists rescue Increased Phosphorylation of FGF14 at S226 in the Tg2576 Mouse Model of Alzheimer's Disease. Exp. Neurol. 295, 1-17. doi:10.1016/j.expneurol.2017.05.005

Isaacson, R. H., Beier, J. I., Khoo, N. K., Freeman, B. A., Freyberg, Z., and Arteel, G. E. (2020). Olanzapine-induced Liver Injury in Mice: Aggravation by High-Fat Diet and protection with Sulforaphane. J. Nutr. Biochem. 81, 108399. doi:10. 1016/j.jnutbio.2020.108399

Ishøy, P. L., Fagerlund, B., Broberg, B. V., Bak, N., Knop, F. K., Glenthøj, B. Y., et al. (2017). No Cognitive-Enhancing Effect of GLP-1 Receptor Agonism in Antipsychotic-Treated, Obese Patients with Schizophrenia. Acta Psychiatr. Scand. 136 (1), 52-62. doi:10.1111/acps.12711

Janson, J., Laedtke, T., Parisi, J. E., O’Brien, P., Petersen, R. C., and Butler, P. C. (2004). Increased Risk of Type 2 Diabetes in Alzheimer Disease. Diabetes 53 (2), 474-481. doi:10.2337/diabetes.53.2.474

Jantrapirom, S., Nimlamool, W., Chattipakorn, N., Chattipakorn, S., Temviriyanukul, P., Inthachat, W., et al. (2020). Liraglutide Suppresses Tau Hyperphosphorylation, Amyloid Beta Accumulation through Regulating Neuronal Insulin Signaling and BACE-1 Activity. Int. J. Mol. Sci. 21 (5), 1725. doi:10.3390/ijms21051725

Kapogiannis, D., Dobrowolny, H., Tran, J., Mustapic, M., Frodl, T., Meyer-Lotz, G., et al. (2019). Insulin-signaling Abnormalities in Drug-Naïve First-Episode Schizophrenia: Transduction Protein Analyses in Extracellular Vesicles of Putative Neuronal Origin. Eur. Psychiatr. 62, 124-129. doi:10.1016/j.eurpsy. 2019.08.012

Kaspar, J. W., Niture, S. K., and Jaiswal, A. K. (2009). Nrf2:INrf2 (Keap1) Signaling in Oxidative Stress. Free Radic. Biol. Med. 47 (9), 1304-1309. doi:10.1016/j. freeradbiomed.2009.07.035

Keshavarzi, S., Kermanshahi, S., Karami, L., Motaghinejad, M., Motevalian, M., and Sadr, S. (2019). Protective Role of Metformin against Methamphetamine Induced Anxiety, Depression, Cognition Impairment and Neurodegeneration in Rat: The Role of CREB/BDNF and Akt/GSK3 Signaling Pathways. Neurotoxicology 72, 74-84. doi:10.1016/j.neuro.2019.02.004

Kim, H.-G. (2019). Cognitive Dysfunctions in Individuals with Diabetes Mellitus. Yeungnam Univ. J. Med. 36 (3), 183-191. doi:10.12701/yujm.2019.00255

Kimura, R., Okouchi, M., Kato, T., Imaeda, K., Okayama, N., Asai, K., et al. (2013). Epidermal Growth Factor Receptor Transactivation Is Necessary for Glucagonlike Peptide-1 to Protect PC12 Cells from Apoptosis. Neuroendocrinology 97 (4), 300-308. doi:10.1159/000345529

Kleinridders, A., Cai, W., Cappellucci, L., Ghazarian, A., Collins, W. R., Vienberg, S. G., et al. (2015). Insulin Resistance in Brain Alters Dopamine Turnover and Causes Behavioral Disorders. Proc. Natl. Acad. Sci. USA 112 (11), 3463-3468. doi:10.1073/pnas.1500877112 
Kleinridders, A., Ferris, H. A., Cai, W., and Kahn, C. R. (2014). Insulin Action in Brain Regulates Systemic Metabolism and Brain Function. Diabetes 63 (7), 2232-2243. doi:10.2337/db14-0568

Koenig, A. M., Mechanic-Hamilton, D., Xie, S. X., Combs, M. F., Cappola, A. R., Xie, L., et al. (2017). Effects of the Insulin Sensitizer Metformin in Alzheimer Disease. Alzheimer Dis. Assoc. Disord. 31 (2), 107-113. doi:10.1097/wad. 0000000000000202

Kosaraju, J., Gali, C. C., Khatwal, R. B., Dubala, A., Chinni, S., Holsinger, R. M. D., et al. (2013a). Saxagliptin: a Dipeptidyl Peptidase-4 Inhibitor Ameliorates Streptozotocin Induced Alzheimer's Disease. Neuropharmacology 72, 291-300. doi:10.1016/j.neuropharm.2013.04.008

Kosaraju, J., Holsinger, R. M. D., Guo, L., and Tam, K. Y. (2017). Linagliptin, a Dipeptidyl Peptidase-4 Inhibitor, Mitigates Cognitive Deficits and Pathology in the 3xTg-AD Mouse Model of Alzheimer's Disease. Mol. Neurobiol. 54 (8), 6074-6084. doi:10.1007/s12035-016-0125-7

Kosaraju, J., Murthy, V., Khatwal, R. B., Dubala, A., Chinni, S., Muthureddy Nataraj, S. K., et al. (2013b). Vildagliptin: an Anti-diabetes Agent Ameliorates Cognitive Deficits and Pathology Observed in Streptozotocin-Induced Alzheimer's Disease. J. Pharm. Pharmacol. 65 (12), 1773-1784. doi:10.1111/ jphp. 12148

Kuhad, A., Bishnoi, M., Tiwari, V., and Chopra, K. (2009). Suppression of NF- $\kappa \beta$ Signaling Pathway by Tocotrienol Can Prevent Diabetes Associated Cognitive Deficits. Pharmacol. Biochem. Behav. 92 (2), 251-259. doi:10.1016/j.pbb.2008. 12.012

Kullmann, S., Heni, M., Hallschmid, M., Fritsche, A., Preissl, H., and Häring, H.-U. (2016). Brain Insulin Resistance at the Crossroads of Metabolic and Cognitive Disorders in Humans. Physiol. Rev. 96 (4), 1169-1209. doi:10.1152/physrev. 00032.2015

Kullmann, S., Heni, M., Veit, R., Scheffler, K., Machann, J., Häring, H.-U., et al. (2017). Intranasal Insulin Enhances Brain Functional Connectivity Mediating the Relationship between Adiposity and Subjective Feeling of Hunger. Sci. Rep. 7 (1), 1627. doi:10.1038/s41598-017-01907-w

Larsen, J. R., Vedtofte, L., Jakobsen, M. S. L., Jespersen, H. R., Jakobsen, M. I., Svensson, C. K., et al. (2017). Effect of Liraglutide Treatment on Prediabetes and Overweight or Obesity in Clozapine- or Olanzapine-Treated Patients With Schizophrenia Spectrum Disorder. JAMA Psychiatry 74 (7), 719-728. doi:10. 1001/jamapsychiatry.2017.1220

Lehrke, M., and Lazar, M. A. (2005). The Many Faces of PPAR $\gamma$. Cell 123 (6), 993-999. doi:10.1016/j.cell.2005.11.026

Li, J., Li, X., Liu, E., Copeland, P., Freudenreich, O., Goff, D. C., et al. (2013). No Effect of Adjunctive, Repeated Dose Intranasal Insulin Treatment on Body Metabolism in Patients with Schizophrenia. Schizophrenia Res. 146 (1), 40-45. doi:10.1016/j.schres.2013.01.034

Lin, Y., Wang, K., Ma, C., Wang, X., Gong, Z., Zhang, R., et al. (2018). Evaluation of Metformin on Cognitive Improvement in Patients With Non-dementia Vascular Cognitive Impairment and Abnormal Glucose Metabolism. Front. Aging Neurosci. 10, 227. doi:10.3389/fnagi.2018.00227

Liu, J., Wang, L. N., and Jia, J. P. (2015). Peroxisome Proliferator-Activated Receptor-Gamma Agonists for Alzheimer's Disease and Amnestic Mild Cognitive Impairment: A Systematic Review and Meta-Analysis. Drugs Aging 32 (1), 57-65. doi:10.1007/s40266-014-0228-7

Liu, W.-C., Wu, C.-W., Tain, Y.-L., Fu, M.-H., Hung, C.-Y., Chen, I.-C., et al. (2018). Oral Pioglitazone Ameliorates Fructose-Induced Peripheral Insulin Resistance and Hippocampal Gliosis but Not Restores Inhibited Hippocampal Adult Neurogenesis. Biochim. Biophys. Acta (BBA) - Mol. Basis Dis. 1864 (1), 274-285. doi:10.1016/j.bbadis.2017.10.017

Liu, Y.-R., Hu, T.-M., Lan, T.-H., Chiu, H.-J., Chang, Y.-H., Chen, S.-F., et al. (2014). Association of the PPAR- $\gamma$ Gene with Altered Glucose Levels and Psychosis Profile in Schizophrenia Patients Exposed to Antipsychotics. Psychiatry Investig. 11 (2), 179-185. doi:10.4306/pi.2014.11.2.179

$\mathrm{Lu}$, J., and Xu, Z. (2019). Efficacy of Intranasal Insulin in Improving Cognition in Mild Cognitive Impairment and Alzheimer Disease: A Systematic Review and Meta-Analysis. Am. J. Ther. 26 (6), e756-e762. doi:10.1097/mjt. 0000000000000926

Lu, X.-Y., Huang, S., Chen, Q.-B., Zhang, D., Li, W., Ao, R., et al. (2020). Metformin Ameliorates A $\beta$ Pathology by Insulin-Degrading Enzyme in a Transgenic Mouse Model of Alzheimer's Disease. Oxidative Med. Cell Longevity 2020, 1-10. doi:10.1155/2020/2315106
Luchsinger, J. A., Perez, T., Chang, H., Mehta, P., Steffener, J., Pradabhan, G., et al. (2016). Metformin in Amnestic Mild Cognitive Impairment: Results of a Pilot Randomized Placebo Controlled Clinical Trial. J. Alzheimers Dis. 51 (2), 501-514. doi:10.3233/jad-150493

Luo, C., Wang, X., Mao, X., Huang, H., Liu, Y., Zhao, J., et al. (2020). Metformin Attenuates Antipsychotic-Induced Metabolic Dysfunctions in MK801-Induced Schizophrenia-like Rats. Psychopharmacology 237 (8), 2257-2277. doi:10.1007/ s00213-020-05524-w

Maddison, D. C., and Giorgini, F. (2015). The Kynurenine Pathway and Neurodegenerative Disease. Semin. Cell Develop. Biol. 40, 134-141. doi:10. 1016/j.semcdb.2015.03.002

Mansur, R. B., Ahmed, J., Cha, D. S., Woldeyohannes, H. O., Subramaniapillai, M., Lovshin, J., et al. (2017). Liraglutide Promotes Improvements in Objective Measures of Cognitive Dysfunction in Individuals with Mood Disorders: A Pilot, Open-Label Study. J. Affective Disord. 207, 114-120. doi:10.1016/j.jad. 2016.09.056

Mansur, R. B., Lee, Y., Subramaniapillai, M., Brietzke, E., and McIntyre, R. S. (2018). Cognitive Dysfunction and Metabolic Comorbidities in Mood Disorders: A Repurposing Opportunity for Glucagon-like Peptide 1 Receptor Agonists? Neuropharmacology 136 (Pt B), 335-342. doi:10.1016/j. neuropharm.2018.01.048

Mao, Y. F., Guo, Z., Zheng, T., Jiang, Y., Yan, Y., Yin, X., et al. (2016). Intranasal Insulin Alleviates Cognitive Deficits and Amyloid Pathology in Young Adult APP Swe/ PS 1dE9 Mice. Aging Cell 15 (5), 893-902. doi:10.1111/acel.12498

Martín, E. D., Sánchez-Perez, A., Trejo, J. L., Martin-Aldana, J. A., Cano Jaimez, M., Pons, S., et al. (2012). IRS-2 Deficiency Impairs NMDA Receptor-dependent Long-Term Potentiation. Cereb. Cortex 22 (8), 1717-1727. doi:10.1093/cercor/ bhr216

McClean, P. L., Jalewa, J., and Hölscher, C. (2015). Prophylactic Liraglutide Treatment Prevents Amyloid Plaque Deposition, Chronic Inflammation and Memory Impairment in APP/PS1 Mice. Behav. Brain Res. 293, 96-106. doi:10. 1016/j.bbr.2015.07.024

McClean, P. L., Parthsarathy, V., Faivre, E., and Hölscher, C. (2011). The Diabetes Drug Liraglutide Prevents Degenerative Processes in a Mouse Model of Alzheimer's Disease. J. Neurosci. 31 (17), 6587-6594. doi:10.1523/jneurosci. 0529-11.2011

McIntyre, R. S., Soczynska, J. K., Woldeyohannes, H. O., Lewis, G. F., Leiter, L. A., MacQueen, G. M., et al. (2007). Thiazolidinediones: Novel Treatments for Cognitive Deficits in Mood Disorders?. Expert Opin. Pharmacother. 8 (11), 1615-1628. doi:10.1517/14656566.8.11.1615

McIntyre, R. S., Soczynska, J. K., Woldeyohannes, H. O., Miranda, A., Vaccarino, A., MacQueen, G., et al. (2012). A Randomized, Double-Blind, Controlled Trial Evaluating the Effect of Intranasal Insulin on Neurocognitive Function in Euthymic Patients with Bipolar Disorder. Bipolar Disord. 14 (7), 697-706. doi:10.1111/bdi.12006

Mehta, V., Parashar, A., Sharma, A., Singh, T. R., and Udayabanu, M. (2017). Quercetin Ameliorates Chronic Unpredicted Stress-Mediated Memory Dysfunction in Male Swiss Albino Mice by Attenuating Insulin Resistance and Elevating Hippocampal GLUT4 Levels Independent of Insulin Receptor Expression. Horm. Behav. 89, 13-22. doi:10.1016/j.yhbeh.2016.12.012

Mert, D. G., Turgut, N. H., Arslanbas, E., Gungor, H., and Kara, H. (2019). The Influence of Quercetin on Recognition Memory and Brain Oxidative Damage in a Ketamine Model of Schizophrenia. Psychiatry Clin. Psychopharmacol. 29 (1), 1-7. doi:10.1080/24750573.2018.1442670

Mi, Y., Qi, G., Fan, R., Qiao, Q., Sun, Y., Gao, Y., et al. (2017). EGCG Ameliorates High-fat- and High-fructose-induced Cognitive Defects by Regulating the IRS/ AKT and ERK/CREB/BDNF Signaling Pathways in the CNS. FASEB j. 31 (11), 4998-5011. doi:10.1096/fj.201700400RR

Mizuki, Y., Sakamoto, S., Okahisa, Y., Yada, Y., Hashimoto, N., Takaki, M., et al. (2020). Mechanisms Underlying the Comorbidity of Schizophrenia and Type 2 Diabetes Mellitus. Int. J. Neuropsychopharmacol. doi:10.1093/ ijnp/pyaa097

Müller, N. (2008). Inflammation and the Glutamate System in Schizophrenia: Implications for Therapeutic Targets and Drug Development. Expert Opin. Ther. Targets 12 (12), 1497-1507. doi:10.1517/14728220802507852

Nakahata, Y., and Yasuda, R. (2018). Plasticity of Spine Structure: Local Signaling, Translation and Cytoskeletal Reorganization. Front. Synaptic Neurosci. 10, 29. doi:10.3389/fnsyn.2018.00029 
Nauck, M. (2014). Update on Developments with SGLT2 Inhibitors in the Management of Type 2 Diabetes. Dddt 8, 1335-1380. doi:10.2147/DDDT. S50773

Nenov, M. N., Laezza, F., Haidacher, S. J., Zhao, Y., Sadygov, R. G., Starkey, J. M., et al. (2014). Cognitive Enhancing Treatment with a PPAR $\gamma$ Agonist Normalizes Dentate Granule Cell Presynaptic Function in Tg2576 APP Mice. J. Neurosci. 34 (3), 1028-1036. doi:10.1523/jneurosci.3413-13.2014

Ott, C. V., Johnson, C. B., Macoveanu, J., and Miskowiak, K. (2019). Structural Changes in the hippocampus as a Biomarker for Cognitive Improvements in Neuropsychiatric Disorders: A Systematic Review. Eur. Neuropsychopharmacol. 29 (3), 319-329. doi:10.1016/j.euroneuro.2019.01.105

Ou, Z., Kong, X., Sun, X., He, X., Zhang, L., Gong, Z., et al. (2018). Metformin Treatment Prevents Amyloid Plaque Deposition and Memory Impairment in APP/PS1 Mice. Brain Behav. Immun. 69, 351-363. doi:10.1016/j.bbi.2017. 12.009

Park, H.-S., Park, S.-S., Kim, C.-J., Shin, M.-S., and Kim, T.-W. (2019). Exercise Alleviates Cognitive Functions by Enhancing Hippocampal Insulin Signaling and Neuroplasticity in High-Fat Diet-Induced Obesity. Nutrients 11 (7), 1603. doi:10.3390/nu1 1071603

Paudel, Y. N., Angelopoulou, E., Piperi, C., Shaikh, M. F., and Othman, I. (2020). Emerging Neuroprotective Effect of Metformin in Parkinson's Disease: A Molecular Crosstalk. Pharmacol. Res. 152, 104593. doi:10.1016/j.phrs.2019. 104593

Pei, B., Yang, M., Qi, X., Shen, X., Chen, X., and Zhang, F. (2016). Quercetin Ameliorates Ischemia/reperfusion-Induced Cognitive Deficits by Inhibiting ASK1/JNK3/caspase-3 by Enhancing the Akt Signaling Pathway. Biochem. Biophysical Res. Commun. 478 (1), 199-205. doi:10.1016/j.bbrc.2016.07.068

Petrov, D., Pedrós, I., Artiach, G., Sureda, F. X., Barroso, E., Pallàs, M., et al. (2015). High-fat Diet-Induced Deregulation of Hippocampal Insulin Signaling and Mitochondrial Homeostasis Deficiences Contribute to Alzheimer Disease Pathology in Rodents. Biochim. Biophys. Acta (BBA) - Mol. Basis Dis. 1852 (9), 1687-1699. doi:10.1016/j.bbadis.2015.05.004

Pillinger, T., Beck, K., Gobjila, C., Donocik, J. G., Jauhar, S., and Howes, O. D. (2017). Impaired Glucose Homeostasis in First-Episode Schizophrenia. JAMA psychiatry 74 (3), 261-269. doi:10.1001/jamapsychiatry.2016.3803

Pipatpiboon, N., Pintana, H., Pratchayasakul, W., Chattipakorn, N., and Chattipakorn, S. C. (2013). DPP4-inhibitor Improves Neuronal Insulin Receptor Function, Brain Mitochondrial Function and Cognitive Function in Rats with Insulin Resistance Induced by High-Fat Diet Consumption. Eur. J. Neurosci. 37 (5), 839-849. doi:10.1111/ejn.12088

Pu, D., Zhao, Y., Chen, J., Sun, Y., Lv, A., Zhu, S., et al. (2018). Protective Effects of Sulforaphane on Cognitive Impairments and AD-like Lesions in Diabetic Mice Are Associated with the Upregulation of Nrf2 Transcription Activity. Neuroscience 381, 35-45. doi:10.1016/j.neuroscience.2018.04.017

Reger, M. A., Watson, G. S., Green, P. S., Baker, L. D., Cholerton, B., Fishel, M. A., et al. (2008). Intranasal Insulin Administration Dose-Dependently Modulates Verbal Memory and Plasma Amyloid- $\beta$ in Memory-Impaired Older Adults. J. Alzheimers Dis. 13 (3), 323-331. doi:10.3233/jad-2008-13309

Renner, D. B., Svitak, A. L., Gallus, N. J., Ericson, M. E., Frey, W. H., II, and Hanson, L. R. (2012). Intranasal Delivery of Insulin via the Olfactory Nerve Pathway. J. Pharm. Pharmacol. 64 (12), 1709-1714. doi:10.1111/j.2042-7158. 2012.01555.x

Robinson, A., Lubitz, I., Atrakchi-Baranes, D., Licht-Murava, A., Katsel, P., Leroith, D., et al. (2019). Combination of Insulin with a GLP1 Agonist Is Associated with Better Memory and Normal Expression of Insulin Receptor Pathway Genes in a Mouse Model of Alzheimer's Disease. J. Mol. Neurosci. 67 (4), 504-510. doi:10. 1007/s12031-019-1257-9

Ruegsegger, G. N., Vanderboom, P. M., Dasari, S., Klaus, K. A., Kabiraj, P., McCarthy, C. B., et al. (2019). Exercise and Metformin Counteract Altered Mitochondrial Function in the Insulin-Resistant Brain. JCI insight 4 (18), e130681. doi:10.1172/jci.insight.130681

Rund, B. R. (2009). Is Schizophrenia a Neurodegenerative Disorder? Nordic J. Psychiatry 63 (3), 196-201. doi:10.1080/08039480902767286

Sa-nguanmoo, P., Tanajak, P., Kerdphoo, S., Jaiwongkam, T., Pratchayasakul, W., Chattipakorn, N., et al. (2017). SGLT2-inhibitor and DPP-4 Inhibitor Improve Brain Function via Attenuating Mitochondrial Dysfunction, Insulin Resistance,
Inflammation, and Apoptosis in HFD-Induced Obese Rats. Toxicol. Appl. Pharmacol. 333, 43-50. doi:10.1016/j.taap.2017.08.005

Sabogal-Guáqueta, A. M., Muñoz-Manco, J. I., Ramírez-Pineda, J. R., LampreaRodriguez, M., Osorio, E., and Cardona-Gómez, G. P. (2015). The Flavonoid Quercetin Ameliorates Alzheimer's Disease Pathology and Protects Cognitive and Emotional Function in Aged Triple Transgenic Alzheimer's Disease Model Mice. Neuropharmacology 93, 134-145. doi:10.1016/j. neuropharm.2015.01.027

Sato, T., Hanyu, H., Hirao, K., Kanetaka, H., Sakurai, H., and Iwamoto, T. (2011). Efficacy of PPAR- $\gamma$ Agonist Pioglitazone in Mild Alzheimer Disease. Neurobiol. Aging 32 (9), 1626-1633. doi:10.1016/j.neurobiolaging.2009.10.009

Sharma, D., Verma, S., Vaidya, S., Kalia, K., and Tiwari, V. (2018). Recent Updates on GLP-1 Agonists: Current Advancements \& Challenges. Biomed. Pharmacother. 108, 952-962. doi:10.1016/j.biopha.2018.08.088

Shiina, A., Kanahara, N., Sasaki, T., Oda, Y., Hashimoto, T., Hasegawa, T., et al. (2015). An Open Study of Sulforaphane-Rich Broccoli Sprout Extract in Patients with Schizophrenia. Clin. Psychopharmacol. Neurosci. 13 (1), 62-67. doi:10.9758/cpn.2015.13.1.62

Shirai, Y., Fujita, Y., and Hashimoto, K. (2012). Effects of the Antioxidant Sulforaphane on Hyperlocomotion and Prepulse Inhibition Deficits in Mice after Phencyclidine Administration. Clin. Psychopharmacol. Neurosci. 10 (2), 94-98. doi:10.9758/cpn.2012.10.2.94

Shirai, Y., Fujita, Y., Hashimoto, R., Ohi, K., Yamamori, H., Yasuda, Y., et al. (2015). Dietary Intake of Sulforaphane-Rich Broccoli Sprout Extracts during Juvenile and Adolescence Can Prevent Phencyclidine-Induced Cognitive Deficits at Adulthood. PLoS One 10 (6), e0127244. doi:10.1371/journal.pone. 0127244

Shoelson, S. E., Lee, J., and Goldfine, A. B. (2006). Inflammation and Insulin Resistance. J. Clin. Invest. 116 (7), 1793-1801. doi:10.1172/JCI29069

Shonesy, B. C., Thiruchelvam, K., Parameshwaran, K., Rahman, E. A., Karuppagounder, S. S., Huggins, K. W., et al. (2012). Central Insulin Resistance and Synaptic Dysfunction in IntracerebroventricularStreptozotocin Injected Rodents. Neurobiol. Aging 33 (2), 430. doi:10.1016/j. neurobiolaging.2010.12.002

Siskind, D., Hahn, M., Correll, C. U., Fink-Jensen, A., Russell, A. W., Bak, N., et al. (2019). Glucagon-like Peptide-1 Receptor Agonists for AntipsychoticAssociated Cardio-Metabolic Risk Factors: A Systematic Review and Individual Participant Data Meta-Analysis. Diabetes Obes. Metab. 21 (2), 293-302. doi:10.1111/dom.13522

Śmieszek, A., Stręk, Z., Kornicka, K., Grzesiak, J., Weiss, C., and Marycz, K. (2017). Antioxidant and Anti-Senescence Effect of Metformin on Mouse Olfactory Ensheathing Cells (mOECs) May Be Associated with Increased Brain-Derived Neurotrophic Factor Levels-An Ex Vivo Study. Int. J. Mol. Sci. 18 (4), 872. doi:10.3390/ijms18040872

Solmaz, V., Çınar, B. P., Yiğittürk, G., Çavuşoğlu, T., Taşkıran, D., and Erbaş, O. (2015). Exenatide Reduces TNF- $\alpha$ Expression and Improves Hippocampal Neuron Numbers and Memory in Streptozotocin Treated Rats. Eur. J. Pharmacol. 765, 482-487. doi:10.1016/j.ejphar.2015.09.024

Souza, C. G., Riboldi, B. P., Hansen, F., Moreira, J. D., Souza, D. G., De Assis, A. M., et al. (2013). Chronic Sulforaphane Oral Treatment Accentuates Blood Glucose Impairment and May Affect GLUT3 Expression in the Cerebral Cortex and Hypothalamus of Rats Fed with a Highly Palatable Diet. Food Funct. 4 (8), 1271-1276. doi:10.1039/c3fo60039d

Spinelli, M., Fusco, S., Mainardi, M., Scala, F., Natale, F., Lapenta, R., et al. (2017). Brain Insulin Resistance Impairs Hippocampal Synaptic Plasticity and Memory by Increasing GluA1 Palmitoylation through FoxO3a. Nat. Commun. 8 (1), 2009. doi:10.1038/s41467-017-02221-9

Sriraksa, N., Wattanathorn, J., Muchimapura, S., Tiamkao, S., Brown, K., and Chaisiwamongkol, K. (2012). Cognitive-Enhancing Effect of Quercetin in a Rat Model of Parkinson's Disease Induced by 6-Hydroxydopamine. Evidence-Based Complement. Altern. Med. 2012, 1-9. doi:10.1155/2012/823206

Suárez-Méndez, S., García-de la Cruz, D. D., Tovilla-Zárate, C. A., Genis-Mendoza, A. D., Ramón-Torres, R. A., González-Castro, T. B., et al. (2020). Diverse Roles of mtDNA in Schizophrenia: Implications in its Pathophysiology and as Biomarker for Cognitive Impairment. Prog. Biophys. Mol. Biol. 155, 36-41. doi:10.1016/j.pbiomolbio.2020.04.004 
Suvisaari, J., Keinänen, J., Eskelinen, S., and Mantere, O. (2016). Diabetes and Schizophrenia. Curr. Diab Rep. 16 (2), 16. doi:10.1007/s11892-015-0704-4

Taber, K. H., Hurley, R. A., and Yudofsky, S. C. (2010). Diagnosis and Treatment of Neuropsychiatric Disorders. Annu. Rev. Med. 61 (1), 121-133. doi:10.1146/ annurev.med.051408.105018

Tao, Q., Miao, Y., Li, H., Yuan, X., Huang, X., Wang, Y., et al. (2020). Insulin Resistance and Oxidative Stress: In Relation to Cognitive Function and Psychopathology in Drug-Naïve, First-Episode Drug-Free Schizophrenia. Front. Psychiatry 11 (1283), 537280. doi:10.3389/fpsyt.2020.537280

Tomé-Carneiro, J., Carmen Crespo, M., Burgos-Ramos, E., Tomas-Zapico, C., García-Serrano, A., Castro-Gómez, P., et al. (2018). Buttermilk and Krill Oil Phospholipids Improve Hippocampal Insulin Resistance and Synaptic Signaling in Aged Rats. Mol. Neurobiol. 55 (9), 7285-7296. doi:10.1007/ s12035-018-0934-y

Too, L. K., Li, K. M., Suarna, C., Maghzal, G. J., Stocker, R., McGregor, I. S., et al. (2016). Deletion of TDO2, IDO-1 and IDO-2 Differentially Affects Mouse Behavior and Cognitive Function. Behav. Brain Res. 312, 102-117. doi:10.1016/ j.bbr.2016.06.018

Viollet, B., Guigas, B., Garcia, N. S., Leclerc, J., Foretz, M., and Andreelli, F. (2011). Cellular and Molecular Mechanisms of Metformin: an Overview. Clin. Sci. 122 (6), 253-270. doi:10.1042/cs20110386

Wang, D.-M., Li, S.-Q., Wu, W.-L., Zhu, X.-Y., Wang, Y., and Yuan, H.-Y. (2014). Effects of Long-Term Treatment with Quercetin on Cognition and Mitochondrial Function in a Mouse Model of Alzheimer's Disease. Neurochem. Res. 39 (8), 1533-1543. doi:10.1007/s11064-014-1343-x

Wang, X., Luo, C., Mao, X.-Y., Li, X., Yin, J.-Y., Zhang, W., et al. (2019). Metformin Reverses the Schizophrenia-like Behaviors Induced by MK-801 in Rats. Brain Res. 1719, 30-39. doi:10.1016/j.brainres.2019.05.023

Wang, Y., Zhao, J., Guo, F.-L., Gao, X., Xie, X., Liu, S., et al. (2020). Metformin Ameliorates Synaptic Defects in a Mouse Model of AD by Inhibiting Cdk5 Activity. Front. Cel. Neurosci. 14, 170. doi:10.3389/fncel.2020.00170

Ward, M., and Druss, B. (2015). The Epidemiology of Diabetes in Psychotic Disorders. The Lancet Psychiatry 2 (5), 431-451. doi:10.1016/S2215-0366(15)00007-3

Watson, G. S., Cholerton, B. A., Reger, M. A., Baker, L. D., Plymate, S. R., Asthana, S., et al. (2005). Preserved Cognition in Patients With Early Alzheimer Disease and Amnestic Mild Cognitive Impairment During Treatment With Rosiglitazone. Am. J. Geriatr. Psychiatry 13 (11), 950-958. doi:10.1097/ 00019442-200511000-00005

Watson, K. T., Wroolie, T. E., Tong, G., Foland-Ross, L. C., Frangou, S., Singh, M., et al. (2019). Neural Correlates of Liraglutide Effects in Persons at Risk for Alzheimer's Disease. Behav. Brain Res. 356, 271-278. doi:10.1016/j.bbr.2018. 08.006

Wennberg, A. M. V., Hagen, C. E., Edwards, K., Roberts, R. O., Machulda, M. M., Knopman, D. S., et al. (2018). Association of Antidiabetic Medication Use, Cognitive Decline, and Risk of Cognitive Impairment in Older People with Type 2 Diabetes: Results from the Population-Based Mayo Clinic Study of Aging. Int. J. Geriatr. Psychiatry 33 (8), 1114-1120. doi:10.1002/ gps. 4900

White, K. E., and Cummings, J. L. (1996). Schizophrenia and Alzheimer's Disease: Clinical and Pathophysiologic Analogies. Compr. Psychiatry 37 (3), 188-195. doi:10.1016/S0010-440X(96)90035-8

Wijtenburg, S. A., Kapogiannis, D., Korenic, S. A., Mullins, R. J., Tran, J., Gaston, F. E., et al. (2019). Brain Insulin Resistance and Altered Brain Glucose Are Related to Memory Impairments in Schizophrenia. Schizophrenia Res. 208, 324-330. doi:10.1016/j.schres.2019.01.031

Wu, R.-R., Zhao, J.-P., Guo, X.-F., He, Y.-Q., Fang, M.-S., Guo, W.-B., et al. (2008a). Metformin Addition Attenuates Olanzapine-Induced Weight Gain in DrugNaive First-Episode Schizophrenia Patients: a Double-Blind, PlaceboControlled Study. Am. J. Psychiatry 165 (3), 352-358. doi:10.1176/appi.ajp. 2007.07010079

Wu, R.-R., Zhao, J.-P., Jin, H., Shao, P., Fang, M.-S., Guo, X.-F., et al. (2008b). Lifestyle Intervention and Metformin for Treatment of AntipsychoticInduced Weight Gain. Jama 299 (2), 185-193. doi:10.1001/jama. 2007.56-b
Xiang, Q., Zhang, J., Li, C.-Y., Wang, Y., Zeng, M.-J., Cai, Z.-X., et al. (2015). Insulin Resistance-Induced Hyperglycemia Decreased the Activation of Akt/CREB in hippocampus Neurons: Molecular Evidence for Mechanism of Diabetes-Induced Cognitive Dysfunction. Neuropeptides 54, 9-15. doi:10.1016/j.npep.2015.08.009

Xiong, H., Zheng, C., Wang, J., Song, J., Zhao, G., Shen, H., et al. (2013). The Neuroprotection of Liraglutide on Alzheimer-like Learning and Memory Impairment by Modulating the Hyperphosphorylation of Tau and Neurofilament Proteins and Insulin Signaling Pathways in Mice. J. Alzheimers Dis. 37 (3), 623-635. doi:10.3233/jad-130584

Xu, Y., Fu, J.-F., Chen, J.-H., Zhang, Z.-W., Zou, Z.-Q., Han, L.-Y., et al. (2018). Sulforaphane Ameliorates Glucose Intolerance in Obese Mice via the Upregulation of the Insulin Signaling Pathway. Food Funct. 9 (9), 4695-4701. doi:10.1039/c8fo00763b

Yao, Y., Han, D. D., Zhang, T., and Yang, Z. (2010). Quercetin Improves Cognitive Deficits in Rats with Chronic Cerebral Ischemia and Inhibits Voltagedependent Sodium Channels in Hippocampal CA1 Pyramidal Neurons. Phytother. Res. 24 (1), 136-140. doi:10.1002/ptr.2902

Yaribeygi, H., Farrokhi, F. R., Butler, A. E., and Sahebkar, A. (2019). Insulin Resistance: Review of the Underlying Molecular Mechanisms. J. Cell Physiol 234 (6), 8152-8161. doi:10.1002/jcp.27603

Yaribeygi, H., Sathyapalan, T., Maleki, M., Jamialahmadi, T., and Sahebkar, A. (2020). Molecular Mechanisms by Which SGLT2 Inhibitors Can Induce Insulin Sensitivity in Diabetic Milieu: A Mechanistic Review. Life Sci. 240, 117090. doi:10.1016/j.lfs.2019.117090

Yi, Z., Fan, X., Wang, J., Liu, D., Freudenreich, O., Goff, D., et al. (2012). Rosiglitazone and Cognitive Function in Clozapine-Treated Patients with Schizophrenia: a Pilot Study. Psychiatry Res. 200 (2-3), 79-82. doi:10.1016/j. psychres.2012.05.020

Youn, J. C., Lee, D. Y., Jhoo, J. H., Kim, K. W., Choo, I. H., and Woo, J. I. (2011). Prevalence of Neuropsychiatric Syndromes in Alzheimer's Disease (AD). Arch. Gerontol. Geriatr. 52 (3), 258-263. doi:10.1016/j.archger.2010.04. 015

Yu, Y., Li, X., Blanchard, J., Li, Y., Iqbal, K., Liu, F., et al. (2015). Insulin Sensitizers Improve Learning and Attenuate Tau Hyperphosphorylation and Neuroinflammation in 3xTg-AD Mice. J. Neural Transm. 122 (4), 593-606. doi:10.1007/s00702-014-1294-z

Zhang, X., Yang, M., Du, X., Liao, W., Chen, D., Fan, F., et al. (2019). Glucose Disturbances, Cognitive Deficits and white Matter Abnormalities in First-Episode Drug-Naive Schizophrenia. Mol. Psychiatry 25, 3220-3230. doi:10.1038/s41380-019-0478-1

Zhao, X., Zeng, Z., Gaur, U., Fang, J., Peng, T., Li, S., et al. (2019). Metformin Protects PC12 Cells and Hippocampal Neurons from H 2 O 2 -induced Oxidative Damage through Activation of AMPK Pathway. J. Cell Physiol 234, 16619-16629. doi:10.1002/jcp.28337

Zhou, L., Chen, T., Li, G., Wu, C., Wang, C., Li, L., et al. (2016). Activation of PPAR Ameliorates Spatial Cognitive Deficits through Restoring Expression of AMPA Receptors in Seipin Knock-Out Mice. J. Neurosci. 36 (4), 1242-1253. doi:10.1523/ jneurosci.3280-15.2016

Zhou, M., Chen, S., Peng, P., Gu, Z., Yu, J., Zhao, G., et al. (2019). Dulaglutide Ameliorates STZ Induced AD-like Impairment of Learning and Memory Ability by Modulating Hyperphosphorylation of Tau and NFs through GSK3ß. Biochem. Biophysical Res. Commun. 511 (1), 154-160. doi:10.1016/j. bbrc.2019.01.103

Conflict of Interest: The authors declare that the research was conducted in the absence of any commercial or financial relationships that could be construed as a potential conflict of interest.

Copyright $\odot 2021$ Chen, Cao, Li, Zeng, Zhang, Wu, Zhang and Cai. This is an openaccess article distributed under the terms of the Creative Commons Attribution License (CC BY). The use, distribution or reproduction in other forums is permitted, provided the original author(s) and the copyright owner(s) are credited and that the original publication in this journal is cited, in accordance with accepted academic practice. No use, distribution or reproduction is permitted which does not comply with these terms. 